Article

\title{
Experimental Investigation on Heat Transfer Enhancement with Passive Inserts in Flat Tubes in due Consideration of an Efficiency Assessment
}

\author{
Dirk Bertsche $^{1, *}$, Paul Knipper ${ }^{2}$, Sebastian Meinicke ${ }^{3}$, Konrad Dubil $^{1}$ and Thomas Wetzel ${ }^{1}$ \\ 1 Institute for Thermal Process Engineering, Karlsruhe Institute of Technology, Kaiserst. 12, \\ 76131 Karlsruhe, Germany; konrad.dubil@kit.edu (K.D.); thomas.wetzel@kit.edu (T.W.) \\ 2 Dieffenbacher GmbH, Heilbronner Str. 20, 75031 Eppingen, Germany; paulknipper@yahoo.de \\ 3 BASF SE, Carl-Bosch-Straße 38, 67063 Ludwigshafen am Rhein, Germany; sebastian.meinicke@gmx.de \\ * Correspondence: dirk.bertsche@protonmail.com; Tel.: +49-711-501-41519
}

check for

updates

Citation: Bertsche, D.; Knipper, P.; Meinicke, S.; Dubil, K.; Wetzel, T.

Experimental Investigation on Heat Transfer Enhancement with Passive Inserts in Flat Tubes in due Consideration of an Efficiency Assessment. Fluids 2022, 7, 53. https://doi.org/10.3390/ fluids7020053

Academic Editor: D. Andrew S. Rees

Received: 28 November 2021 Accepted: 19 January 2022

Published: 24 January 2022

Publisher's Note: MDPI stays neutral with regard to jurisdictional claims in published maps and institutional affiliations.

Copyright: (C) 2022 by the authors. Licensee MDPI, Basel, Switzerland. This article is an open access article distributed under the terms and conditions of the Creative Commons Attribution (CC BY) license (https:// creativecommons.org/licenses/by/ $4.0 /)$.

\begin{abstract}
This paper presents results of an experimental investigation on pressure drop and heat transfer for a wide range of Reynolds and Prandtl numbers ranging from $8<\operatorname{Pr}<60$ and $40<\operatorname{Re}<3500$, for flat tubes without and with passive inserts. For three different kinds of passive insert designs, the impact on heat and momentum transfer due to coaction of the total set of passive inserts with different shape and amount was investigated. Experimental results were analyzed regarding two main aspects: Heat transfer mechanisms and pressure drop induced by friction and form drag forces due to the presence of different shapes. After heat and momentum transfer mechanisms for each passive insert design were analyzed, heat transfer and pressure drop enhancement were compared to each other, leading to an efficiency discussion. Different concepts for efficiency evaluation, which are cited in literature, were applied to the presented experimental data. Pros and cons of the different concepts are discussed. Finally, we propose an equation for evaluation of total performance, which fully respects the energetic and exergetic aspects of heat transfer and pressure drop enhancement.
\end{abstract}

Keywords: heat transfer coefficient; pressure drop; flat tubes; passive inserts; energy; exergy; momentum and heat transfer; efficiency

\section{Introduction}

Numerous investigations on heat and momentum transfer with passive inserts in tubes and pipes have been published in the past. Many of them deal with the influence of the shape or the arrangement of single passive inserts inside the channels, using experimental or numeric methods. Most of those investigations are focused on the fully turbulent flow regime, as the Reynolds number is higher than $\operatorname{Re}>10,000$ [1-4]. Various geometrical shapes of passive inserts have been investigated in the past. From so called "dimples", which are primarily designed to stop the formation or realize a reformation of the boundary layers [5], to passive inserts such as pins, which will induce flow detachment and turbulence downstream [6-9]. Such "pins" are columns with arbitrary cross sectional shape such as circle, oval, drop, or diamond, with an insert height to channel height ratio of one, meaning that the cylindrical passive insert stretches from bottom to top of the channel. Other types of passive inserts, which are mainly used for minimizing the thermal boundary layer, are characterized by a lower insert height to channel height ratio.

Their geometrical shape is often designed in order to realize a short reattachment length enhancing the heat transfer [10]. Dewan et al. [11] reviewed over 100 publications dealing with heat transfer enhancement using passive inserts with various geometrical shape and arrangement inside different kinds of channels. The vast majority were investigated for air or water flow, which correlates to Prandtl numbers Pr $<7$. Significantly fewer investigations have been performed for heat transfer enhancement with passive 
inserts for coolant fluids such as water-glycol mixtures or different kinds of oil with $\operatorname{Pr}>7$. In addition, most of the investigations published so far have been performed for fully turbulent flow.

Passive inserts used in air or gas flow are mainly designed for heat transfer enhancement in turbulent flow regime since most industrial heat exchanger applications operate in this. Nonetheless, the situation may be different for industrial heat exchanger applications using coolant fluids or oils. In addition to their typically higher Prandtl number, which results from higher viscosity and density, the Reynolds number is significantly lower in industrial applications, i.e., in heater core or radiator. In addition, for fluids with $\operatorname{Pr}>7$ (increased viscosity), the induced pressure drop, which comes along with heat transfer enhancement, becomes more important, as the pumping power or energy consumption over time will increase significantly more compared with fluids with $\operatorname{Pr}<7$. Consequently, an optimum shape of passive inserts used for air or pure water flow may be designed completely differently as for fluids with higher Prandtl number. For the latter, it may be even efficient to first induce turbulence, which may not be present without passive inserts for $\operatorname{Re}<10,000$.

As published data are sparse for the use of passive inserts for $\operatorname{Pr}>7$ and $\operatorname{Re}<4000$, this contribution is specifically focused of the influence of passive inserts on heat and momentum transfer in this Prandtl and Reynolds number range. It was the aim of this investigation to elaborate the heat transfer mechanisms, which are present with and without passive inserts. Pressure drop was analyzed simultaneously in order to gain insight in the different mechanisms behind it, such as surface shear stress or from local pressure gradients in the wake of inserts. This contribution is focused on flat tubes. They are widely used in industry with and without passive inserts for flat tube heat exchangers, such as the heater core in cabin or room heating systems, low temperature radiators, or other heat exchangers used especially in the automotive industry.

The operating conditions were set such as to achieve Prandtl and Reynolds number ranges $8<\operatorname{Pr}<60$ and $40<\operatorname{Re}<3500$. Based on 434 data points analysis on the influence of three different passive insert types on pressure drop, heat transfer, and flow regime boundaries are presented. The increase in form and friction drag pressure drop is compared to the increase in heat transfer, resulting from induced turbulences, forcing a reformation of boundary layers and increasing the heat transferring surface. The contradicting goals of minimizing the increase in pressure drop while increasing heat transfer significantly are finally analyzed using available and extended criteria to rate the efficiency of passive inserts.

In this contribution, we focus on the situation with a set of passive inserts inside a flat tube. In contrast with many other investigations dealing with passive inserts, we do not compare the impact of single passive inserts with different shape but same height, length, etc., or vice versa, and we do not investigate the local phenomena around one single passive insert. Instead, we discuss the impact of the co-action of the total set of passive inserts used in one flat tube. In addition, we want to keep either heat transfer or pressure drop constant throughout the variations of the inserts, which is in line with the situation in most practical applications. An example for this is an upper limit in the allowable pressure drop due to, e.g., pump capacity. At the same time this is a suitable way to enable comparisons of the effects of different insert shape and arrangement over a wide range of Re and Pr.

Since the testing infrastructure has already been used for determination of heat transfer and pressure drop data for other purposes, some of the following chapters, which are labeled respectively, have already been described in other publications of the authors. This is why we thoroughly reference and indent these text passages in the following to avoid self-plagiarism.

\section{Methods}

We described the methods in a previous publication:

Heat transfer coefficients were determined in this investigation by cooling down a hot liquid flow towards a cold one in a parallel flow arrangement. The test facility used 
was exactly the same as described in [12-15]. For technical details, the reader is referred to one of these publications. Figure 1 shows the process flow diagram for the hot flow side of the experimental setup, including the test section itself (reproduced with permission from Section 2, page 3 in [16], published by Elsevier 2021).
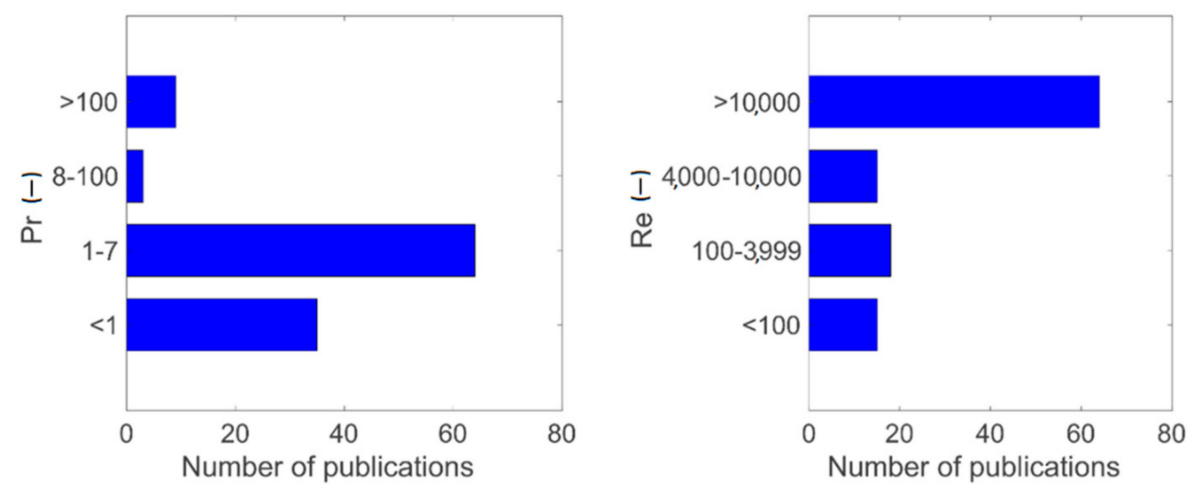

Figure 1. Overview of publications dealing with passive inserts classified into Reynolds and Prandtl number range.

\subsection{Test Section}

We also described the first part of the following chapter test section in a previous publication:

A hot flow was cooled down in the measuring channel. This test rig was designed to test different pipe geometries with different heat flow directions (heated and cooled flow inside the circular pipe measuring channel, see Bertsche et al. [14,15]). A heat exchangerlike approach was chosen instead of, e.g., an electrically heated pipe, which is described in the following. This easily allows mimicking heat exchanger conditions and realizing a thermal boundary condition close to constant wall temperature. The test section consisted of seven geometrically identical channels which were formed by eight aluminum half-shells (see Figures 2-4). This arrangement was chosen to ensure the desired thermal boundary condition and checked using numerical calculations. For the exact positioning $(\mathrm{x}, \mathrm{y})$ of two half shells onto each other, dowel pins were used to ensure a "perfect" flat tube.

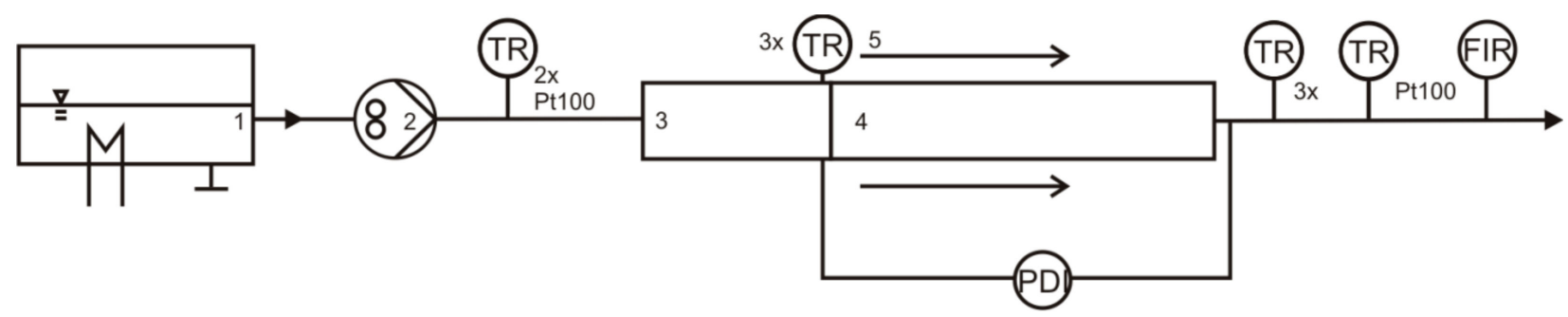

Figure 2. Process flow diagram of the test facility: 1, thermostat; 2 , gear pump; 3 , inlet section; 4 , test section; 5, cold co-current flow to develop thermal boundary condition desired. Reproduced with permission from [16], published by Elsevier 2021.

High-precision milling was used to secure perfect contours of the flat tube and a smooth surface quality with a resulting peak-to-trough roughness height of $\mathrm{k}=1.3 \mu \mathrm{m}$. According to [17] and the investigated Reynolds number range, the assumption of a technically smooth pipe was therefore valid. The length of the aluminum half shells was $220 \mathrm{~mm}$, its width was $52 \mathrm{~mm}$, and the hydraulic diameter of the flat tube was $2.1 \mathrm{~mm}$ with a height to width ratio of the flat tube $\mathrm{h} / \mathrm{w}=0.075$. The aluminum half shell contained the contour of two flat tube channels with $14.7 \mathrm{~mm}$ in width, $1.12 \mathrm{~mm}$ in height and $220 \mathrm{~mm}$ in length. The thickness of the half shells, i.e., the distance between the hot and cold channels was $28 \mathrm{~mm}$. The channel in the center was the measuring channel with a cross-section area 
Ac and a hydraulic diameter to length ratio of 0.01 . The channels above and below were necessary for homogeneously cooling the measuring channel. The neighboring "secondary" hot channels of the two "primary" cold channels below and above the measuring channel provided homogeneous conditions for those "primary" cold channels, etc. In total, seven flat tube channels were subject to alternate hot (temperature $\mathrm{T}_{\text {hot,in }}$ ) and cold (temperature $\left.\mathrm{T}_{\text {cold,in }}\right)$ flow. Due to this arrangement, the thermal boundary condition at the flat tube's wetted surface was close to a constant wall temperature (uniform wall temperature). This was checked by nine thermocouples, which were used to determine the homogeneous temperature inside the aluminum shell in the drilled holes, albeit only three are indicated in Figure 3 on the right.

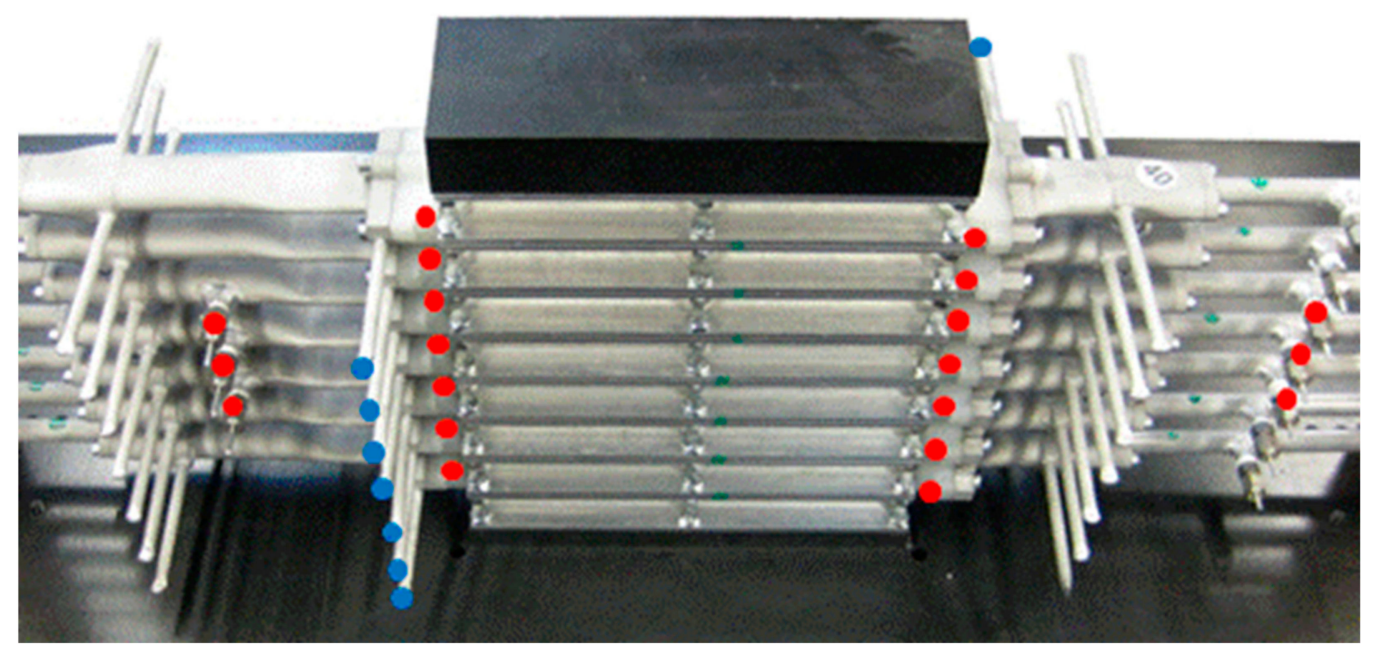

Figure 3. Test section and supply pipes without insulation (flow direction from left to right); access points for temperature and pressure sensors are marked in red and blue respectively. Reproduced with permission from [16], published by Elsevier 2021.
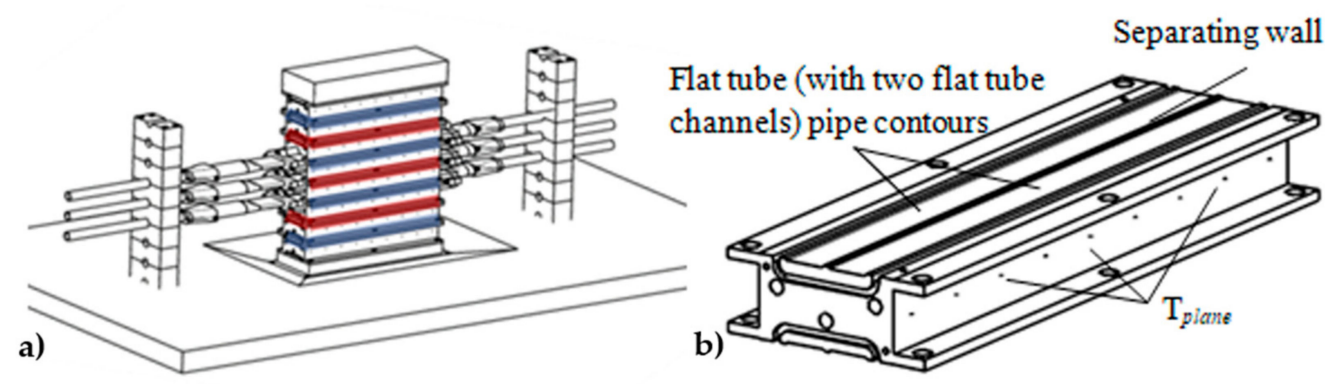

Figure 4. Test section with eight stacked aluminum half shells and supply pipes (a) and enlarged view of one of the half-shells (b) (for clarity, only three of the seven supply pipes are shown). Reproduced with permission from [16], published by Elsevier 2021.

The whole setup including supply pipes and a half-shell stack was wrapped in thermally insulating material. Sheath resistance thermometers at the inlet and outlet were used to determine the averaged fluid temperatures $T_{\text {hot,in }}$ and $T_{\text {hot,out }}$. Homogeneity of the inlet temperature was ensured using mixing elements in the supply line and at the outlet. In addition, two sensors were placed side by side with respect to the mixing effect of the sudden cross section expansion at the end of the measurement channel and at the start of the measurement channel to account for the changed cross section of the supply pipes. The signals of the parallel sensors were arithmetically averaged. Pressure drop sensors were used in order to determine the pressure drop over the measuring channel. One of the eight aluminum half shells, which was used to investigate the flow in flat tube with passive inserts is shown in Figure 4. As one flat tube consisted of two identical separate 
channels, a separating wall is shown in the middle of the channel, as it is also presented in Figure 3 for the flat tube without passive inserts (reproduced with permission from Section 2.1, pages 3-4 in [16], published by Elsevier 2021).

In addition to a flat tube channel without passive inserts, two other test sections with passive inserts have been used, which are both shown in Figure 4. On the left side, one aluminum shell with the contour of a flat tube with 132 bump-like shaped passive inserts as typically used in industry and called there "winglets" is shown. A detailed investigation on heat transfer enhancement and mechanisms with this kind of passive inserts was published by Forooghi et al. [18]. The flat tube on the right of Figure 4 is equipped with 35 cylindrical pins with a diameter of $\mathrm{d}=0.6 \mathrm{~mm}$.

The detailed geometry of the passive inserts is presented in Figures 5 and 6 . The left sides in Figures 5 and 6 show a short section of the whole flat tube with 2 out of the 33 identical winglet rows and one out of the seven periodic pin patterns. One complete channel is shown in a perspective view on the right sides in Figures 5 and 6. It should be noted that the number of pins in the channel shown in Figure 6 is significantly smaller than that of the winglets in the tube according to Figure 5. The reason for this is that the pin channel is the result of a design process aiming at similar heat transfer at reduced pressure drop compared with the winglet channel over the whole Pr and Re range investigated, as is discussed in Sections 3 and 4.
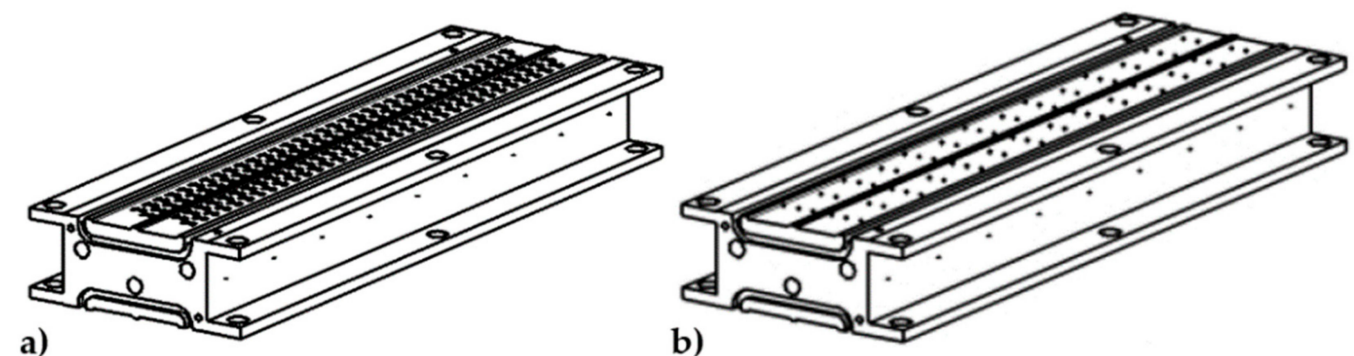

Figure 5. Aluminum half shells with passive inserts. (a): Contour of flat tube within aluminum shell with passive inserts used in automotive industry (reproduced with permission from [16], published by Elsevier 2021). (b): Contour of flat tube within aluminum shell with cylindrical pins with $\mathrm{d}=0.6 \mathrm{~mm}$.
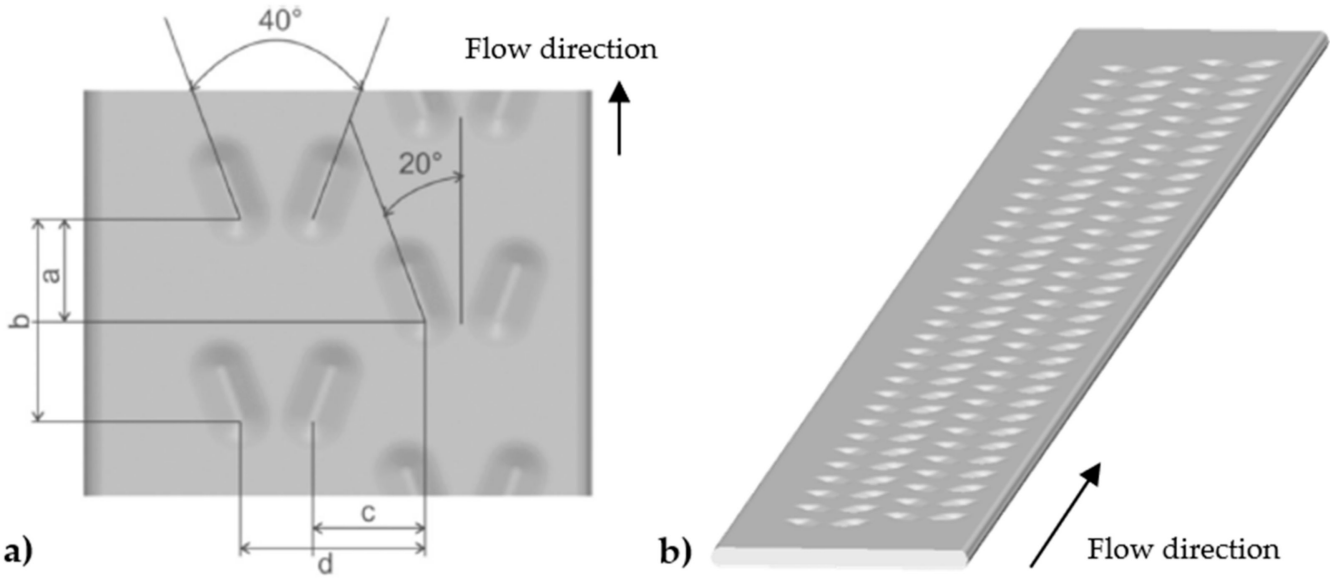

Figure 6. Flat tube with passive inserts ("winglets") used in automotive industry for flat tube heat exchangers. (a): Detailed geometry of passive inserts. $\mathrm{b} / \mathrm{a}=2 ; \mathrm{c} / \mathrm{d}=0.6$. The ratio of the insert height to channels height is 0.325 . (b): Left channel of the corresponding flat tube with $1=220 \mathrm{~mm}$ length and passive inserts used in automotive industry. Reproduced with permission from [16], published by Elsevier 2021.

A third kind of passive insert type was investigated, which consisted of several waveshaped bumps stretching over the whole width of the channel. Every bump was placed 
transverse to the flow direction, as shown in Figure 7 on the right. Alternately one of those bumps, with a cross sectional shape, as shown in Figure 8, was turned into the channel, forcing a decrease in cross section, followed by another wave-shaped bump, which was turned outside the channel, enlarging the cross section of the flat tube locally. The bumps at the top were displaced compared with the ones at the bottom to realize a constant cross section of the flat tube over the entire flat tube length. Table 1 shows the geometrical parameters, which describe the wave-shape as well as the arrangement of all those passive inserts inside the flat tube channel.

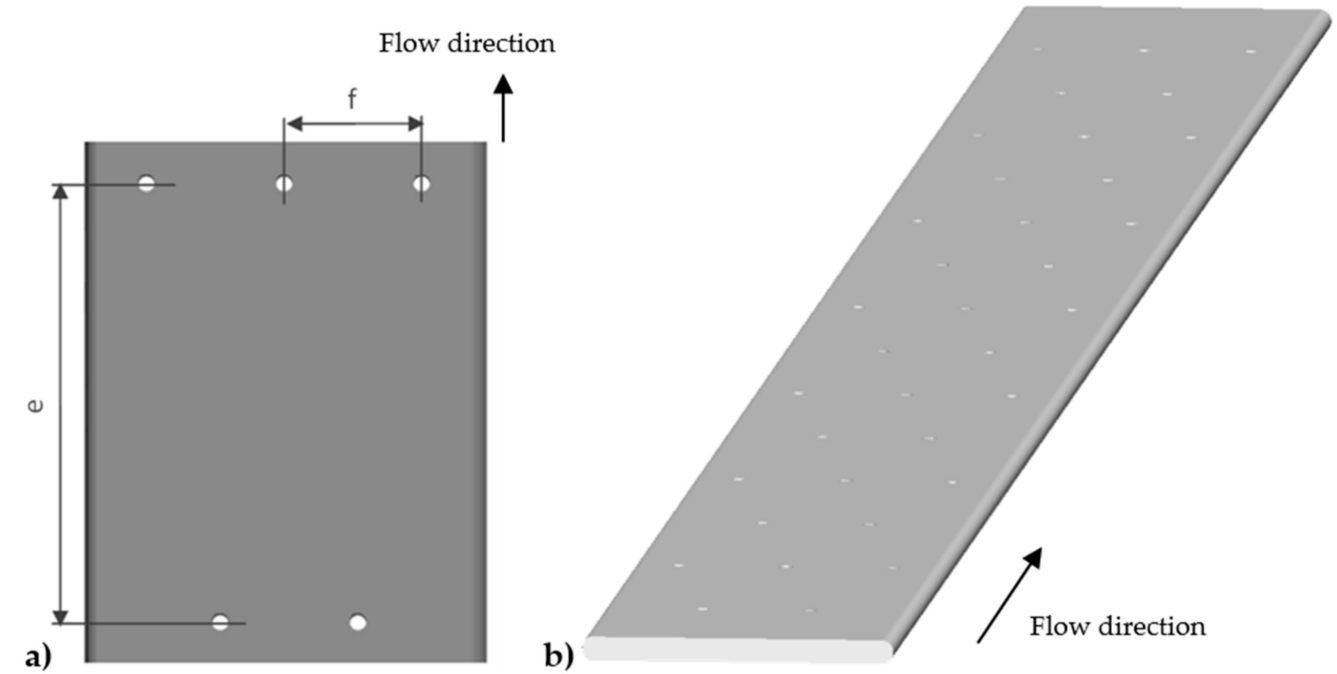

Figure 7. Flat tube with cylindrical pins. (a): Detailed geometry of passive inserts. Pin diameter $\mathrm{d}=0.6 \mathrm{~mm}, \mathrm{e}=16.3 \mathrm{~mm}, \mathrm{f}=5.4 \mathrm{~mm}$. (b): Flat tube with $\mathrm{l}=220 \mathrm{~mm}$ length and passive inserts.

a)

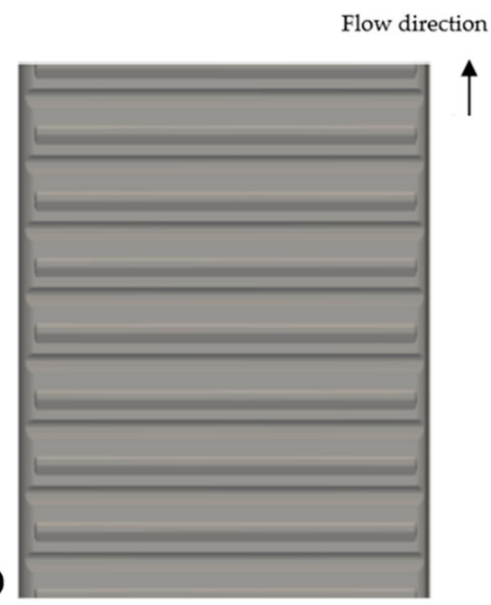

b)

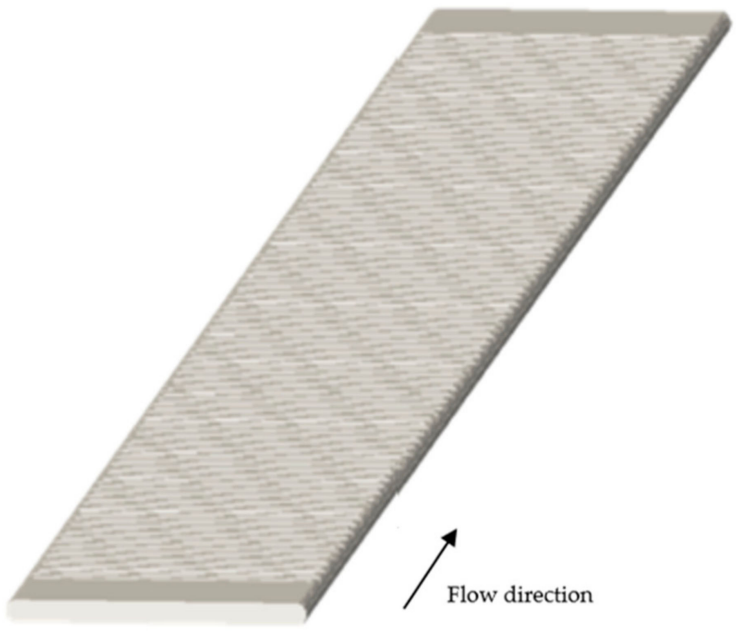

Flow direction $\longrightarrow$

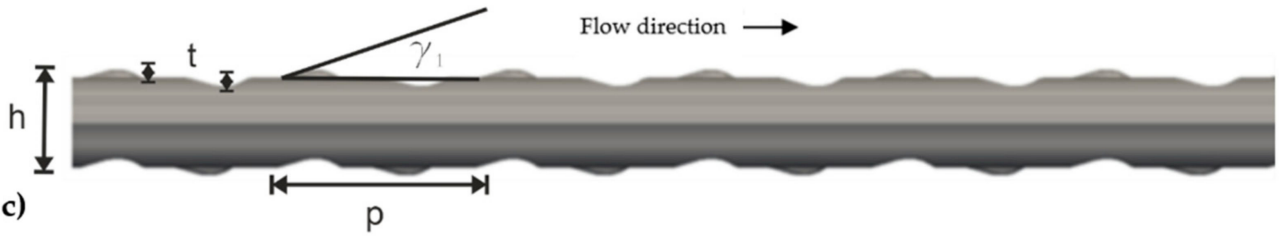

Figure 8. Entire flat tube (a) and parts of the flat tube with wave-shapes bumps in top (b) and side view (c).

The questions to be answered were, which flow modifications or phenomena are induced by the three different passive insert types and in what way do they affect heat transfer and pressure drop? The bulk and boundary layers will be influences in different 
ways with the present passive inserts, which is why on the one hand we considered different portions of heat transfer realized by minimizing boundary layer thickness and inducing turbulence in core flow and on the other hand pressure drop induced by friction and drag forces. To this end, particularly the ratio between friction and form drag induced by the three different passive insert types is discussed.

Table 1. Geometrical parameters for wave-shaped bumps inside the flat tube channel.

\begin{tabular}{cc}
\hline Parameter & Value \\
\hline Number of bumps/- & 168 \\
$\mathrm{t} / \mathrm{h} /-$ & 0.12 \\
$\mathrm{p} / \mathrm{h} /-$ & 11.6 \\
$\gamma_{1} /-$ & $16^{\circ}$ \\
\hline
\end{tabular}

\subsection{Hydrodynamic Inlet Boundary Condition}

Since the test section was used in a previous publication, the hydrodynamic inlet boundary condition was described in a previous publication:

The pressure drop, the hydrodynamic entry length, and the transition point between the different flow regimes (laminar, transitional, and turbulent flow regime) strongly depend on the inlet condition, as thoroughly investigated by Ghajar and Tam [19-21] andto a lesser extent though-also depend on the surface roughness. The inlet configuration chosen in the present work was named "square edged" by Ghajar and Tam [21] and is realized by a sharp step geometry directly at the inlet of the flat tube measurement channel (see Figure 9) with a step height to flat tube characteristic length of 0.21 . This kind of inlet configuration is typical for the vast wealth of existing data and typical for heat exchangers in general.

Flow direction

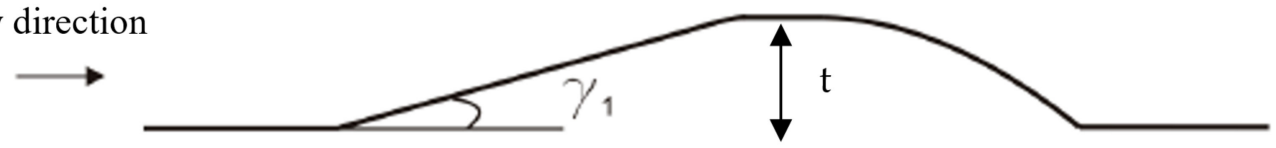

Figure 9. Geometrical shape of the wave-shaped bump, cross section at an angle of 90 degrees to flow direction.

The supply pipes (see Figure 3) expand gradually into a wide channel with a flat tube cross section (inlet chamber) before abruptly experiencing a step jump into the measurement pipe. The supply pipe contracts with a very small contraction ratio to avoid or minimize recirculation and detachment zones. It is followed by an inlet chamber or smoothing section to secure reproducible hydrodynamic inlet conditions for all investigated flow rates or temperature levels.

As indicated in Figure 3, a flat tube channel form is present for the smoothing section, because this test facility was originally designed to work for flat tubes, as commonly used in compact heat exchangers for automotive applications. Therefore, a minimum of pressure drop occurs at the inlet section using a flat tube as test channel geometry. However, we calculated this additional pressure drop using available correlations from the literature [22] and subtracted it from the measured overall pressure drop to obtain a corrected value for the flat tube channel only. The influence of surface roughness on transition can be neglected, since the present peak-to-trough roughness height was calculated to $\mathrm{k}=1.3 \mu \mathrm{m}$ using Nikuradse's laws of flow in rough pipes (reproduced with permission from Section 2.2, pages $4-5$ in [16], published by Elsevier 2021).

\subsection{Thermal Boundary Condition}

We described the thermal boundary condition in a previous publication: 
A co-current flow condition with separately adjustable hot and cold flow rates was realized in combination with a symmetric arrangement of the flat tube channels. Once the same heat transfer conditions, including similar values of the heat transfer coefficients, were present in the hot and the cold flow flat tubes, a homogeneous temperature distribution in the symmetry plane of the aluminum shells (see $T_{\text {plane }}$ in Figure 10) was established. This provided an excellent option for evaluating the heat transfer coefficients (see Section 3) when slightly adjusting the mass flow rates in the primary heating pipes next to the measuring one.

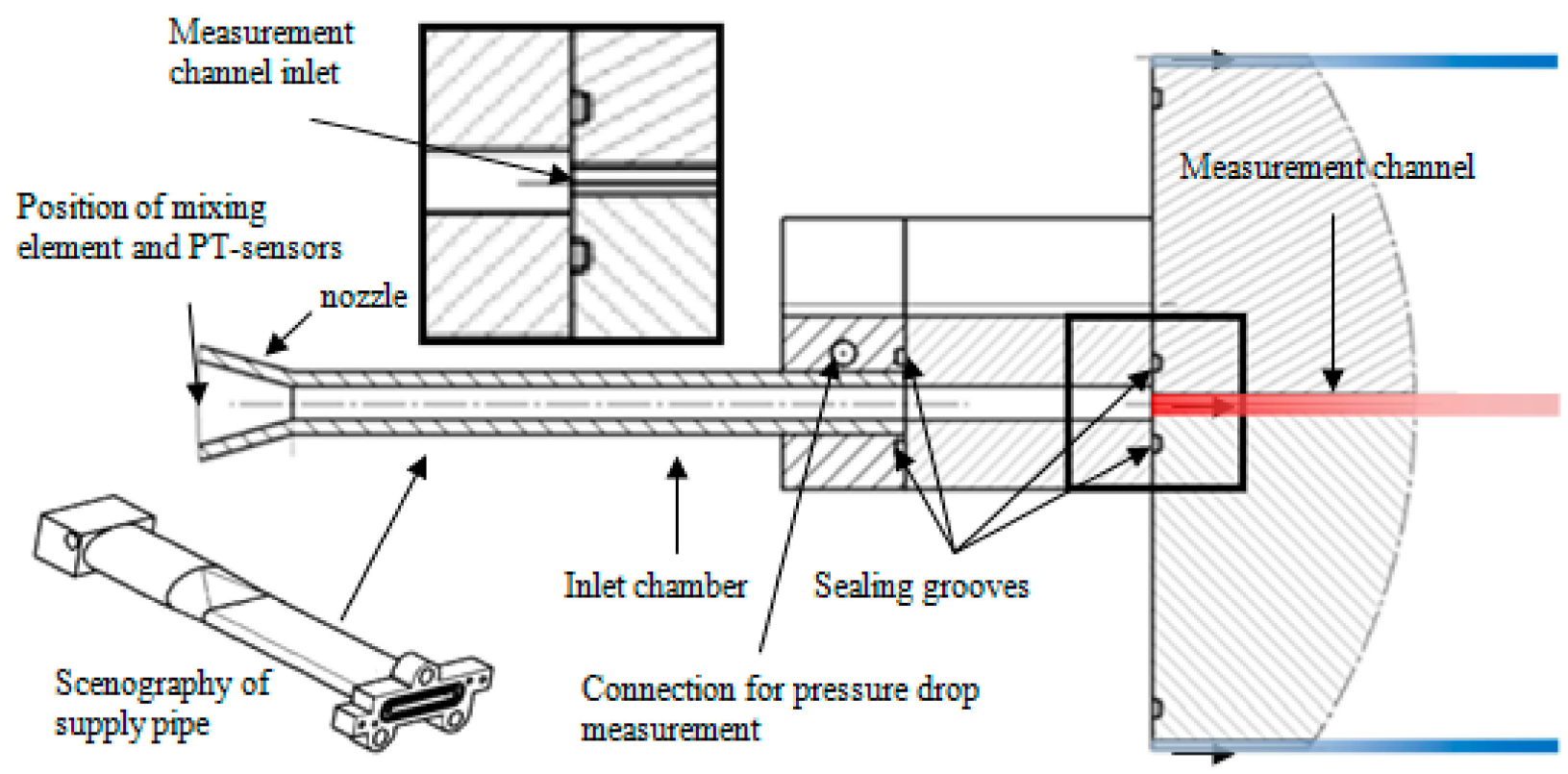

Figure 10. Cross-sectional view of the supply pipe and the beginning of the flat tube measuring channel. Reproduced with permission from [16], published by Elsevier 2021.

Although a non-homogeneous wall temperature was present at the heat transfer surface, the temperature difference in the flat tube measurement channel was 10 times the change in temperature at the heat transferring wall along the flat tube in flow direction. Thus, the heat transfer coefficients determined can be compared with correlations valid for uniform wall temperature conditions.

The Prandtl number was evaluated with the arithmetic mean of inlet and outlet temperature values. In order to achieve constant Pr-numbers over a wide range of varied $\mathrm{Re}$, the inlet temperature was slightly adjusted with changing Re. In this way, a maximum variation of the Prandtl number of $\operatorname{Pr} \pm 1$ could be achieved. The ratio $\left(\operatorname{Pr} / \operatorname{Pr}_{W}\right)^{0.11}$ was determined for all the following heat transfer data with values of $(\operatorname{Pr} / \operatorname{Pr})^{0.11}<1.01$. The Reynolds number was determined using the characteristic length of the flat tube.

The temperature difference along the flat tube was chosen to be small enough to achieve quasi-isothermal conditions, which in turn enabled the use of constant thermophysical properties in the evaluation procedure. However, these small temperature differences also applied to the evaluation of the heat transfer coefficients. Obviously, the accuracy of this evaluation would improve with increasing temperature differences. Therefore, a compromise between both requirements was sought based on a careful uncertainty analysis following the guide for determination of uncertainty in measurement (GUM) [23]. For further details concerning the measurement uncertainty and reproducibility, the reader is referred to one of the following publications [12-16] (reproduced with permission from Section 2.3, pages 5-6 in [16], published by Elsevier 2021).

The uncertainty of all measuring devices and the subsequent uncertainties of the target values Nusselt number and pressure drop are listed in Table 2. 
Table 2. Uncertainty of all measuring devices and resulting uncertainties of target values heat transfer and pressure drop.

\begin{tabular}{cc}
\hline Measurement Device & Uncertainty \\
\hline Resistance thermometer Pt100 with data logger: NI9213 (National Instruments) & $\Delta \mathrm{T} \leq \pm 0.023 \mathrm{~K}$ \\
\hline $\begin{array}{c}\text { Thermocouple Typ K with data logger: NI9203 (National Instruments) and external } \\
\text { reference temperature }\end{array}$ & $\Delta \mathrm{T} \leq \pm 0.14 \mathrm{~K}$ \\
\hline $\begin{array}{c}\text { Coriolis mass flow meter CMFS015M with evaluation electronics MVD 2500D } \\
\text { (Emerson Process Management) }\end{array}$ & $\Delta \dot{\mathrm{M}} \leq \pm 0.05 \%$ \\
\hline Target Values & Uncertainty \\
\hline Nusselt number/- & $\Delta \mathrm{Nu} \leq \pm 12 \%$ \\
\hline Pressure drop/mbar & $\Delta \mathrm{p} \leq \pm 8.5 \%$ \\
\hline
\end{tabular}

In order to validate setup and procedure, comprehensive experimental results were determined for cylindrical pipe flow at the same test facility and compared with the literature in $[12,14,15]$ showing an excellent match to the literature. Thus, the test facility and the data processing can be considered as validated. The results for the flat tube flow are compared to literature in addition to that; please see Section 4.

\section{Evaluation Procedure}

We described the evaluation procedure in a previous publication:

\subsection{Determination of Heat Transfer Coefficients from Measured Data}

Equation (1) was used for the calculation of the Nusselt number, which was calculated from the measured values of the inlet temperature, $\mathrm{T}_{\text {hot,in, }}$, the outlet temperature, $\mathrm{T}_{\text {hot,out }}$, and the temperature in the planes between the flat tube measuring channel and its direct neighbors, $\mathrm{T}_{\text {plane, }}$ as well as the mass flow rate, $\dot{\mathrm{M}}$, of the cold flow.

$$
\begin{gathered}
\mathrm{Nu}=\frac{\alpha \cdot \mathrm{d}_{\mathrm{h}}}{\lambda}=\frac{\mathrm{d}_{\mathrm{h}}}{\mathrm{A} \cdot \lambda} \cdot\left(\frac{2}{\dot{\mathrm{M}} \cdot \mathrm{c}_{\mathrm{p}} \cdot \ln \frac{\mathrm{T}_{\mathrm{hot}, \text { in }}-\mathrm{T}_{\text {plane }}}{\mathrm{T}_{\text {hot,out }}-\mathrm{T}_{\text {plane }}}}-\mathrm{R}_{\mathrm{Al}}\right)^{-1} \\
\mathrm{R}_{\mathrm{Al}}=\frac{1}{2 \pi \cdot \mathrm{L} \cdot \lambda_{\mathrm{Al}}} \cdot \operatorname{arcosh}\left(\frac{2 \cdot \mathrm{e}}{\mathrm{d}_{\mathrm{h}}}\right)
\end{gathered}
$$

Figure 11 shows the system boundary for determining the Nusselt number $\mathrm{Nu}$ from an energy balance. The heat is transferred from the neighboring hot fluids across the flat tube walls through the planes of homogeneous temperature distribution, $T_{\text {plane }}=$ const in the aluminum shells and finally across the heat-transferring surface, $\mathrm{A}$, to the cold flat tube measuring channel. The heat transfer resistance of the aluminum shell $\mathrm{R}_{\mathrm{Al}}$ was determined using Equation (3) taken from [24] and depends on the geometry of the aluminum shell, i.e., the distance of pipe center to isothermal plane $\left(\mathrm{T}_{\text {plane }}\right)$, $\mathrm{e}$, the hydraulic diameter, $\mathrm{dh}$ and length, 1 as well as the heat conductivity $\lambda_{\mathrm{Al}}$ of the aluminum. A detailed derivation of Equation (1) is presented in [15].

\subsection{Determination of Friction Factor from Measured Data}

The pressure drop, $\Delta \mathrm{p}$, along the measuring channel was determined as described in [15]. To express the friction factor $\xi$ we used the Darcy friction factor $f_{D}$, which is determined with the total pressure drop of the flat tube.

$$
\mathrm{f}_{\mathrm{D}}=\frac{\Delta \mathrm{p}}{\mathrm{L}} \cdot \frac{2 \cdot \mathrm{d}_{\mathrm{h}}}{\rho \cdot \mathrm{u}^{2}}
$$

The mean flow velocity was determined from the mass flow, $\dot{M}$, and density, $\rho$, measured in the coriolis mass flow meter. Since pressure drop in flat tubes without and with 
passive inserts will be induced by friction and form drag forces, the pressure drop can be separated in so-called form drag pressure drop $\mathrm{dp}_{\mathrm{fo}} / \mathrm{dx}$ and friction drag pressure drop $\mathrm{dp}_{\mathrm{fr}} / \mathrm{dx}$. The friction fraction $\mathrm{x}_{\mathrm{fr}}$ represents the fraction of the friction drag pressure drop $\mathrm{dp}_{\mathrm{fr}} / \mathrm{dx}$ on the measured total pressure drop $\mathrm{dp}_{\mathrm{fr}} / \mathrm{dx}+\mathrm{dp}_{\mathrm{fo}} / \mathrm{dx}$. In order to allow a comparison of both, form pressure drop and friction pressure drop fraction on the total pressure drop of flat tube without and with passive inserts, an approach by Della Torre et al. [25] was used.

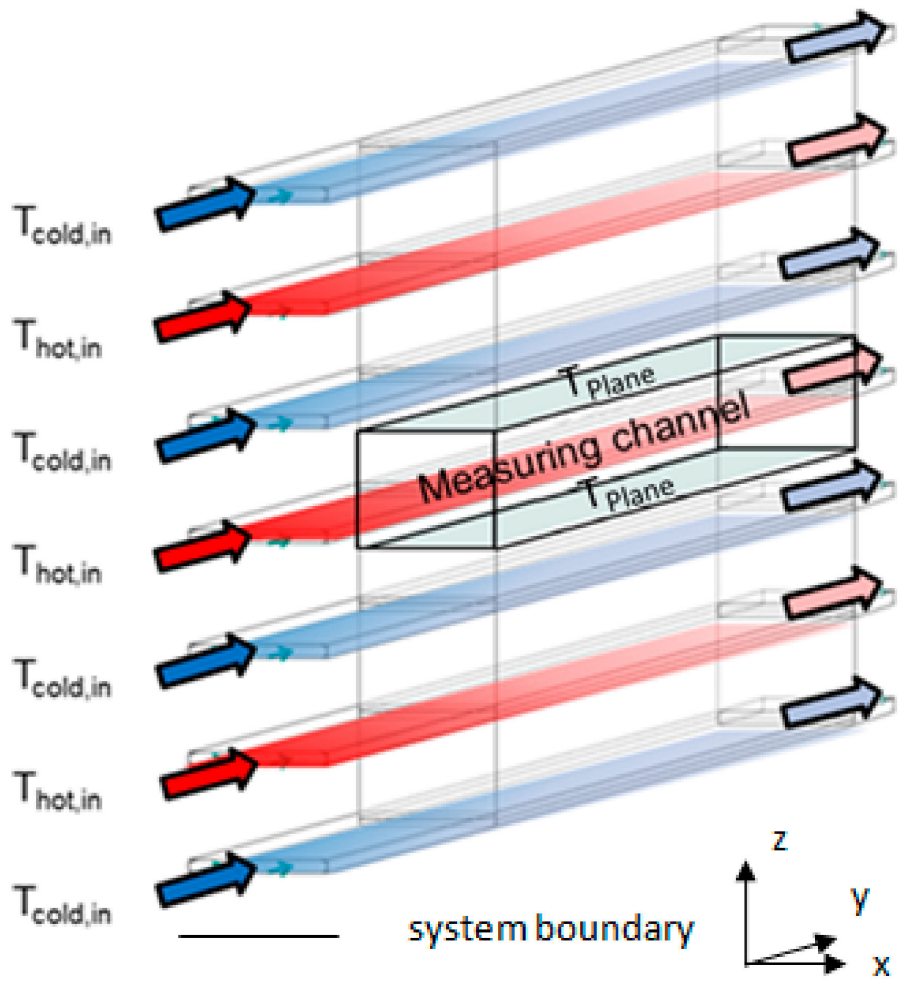

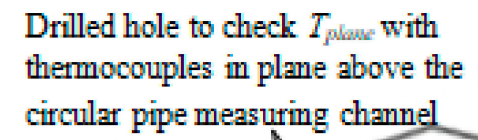

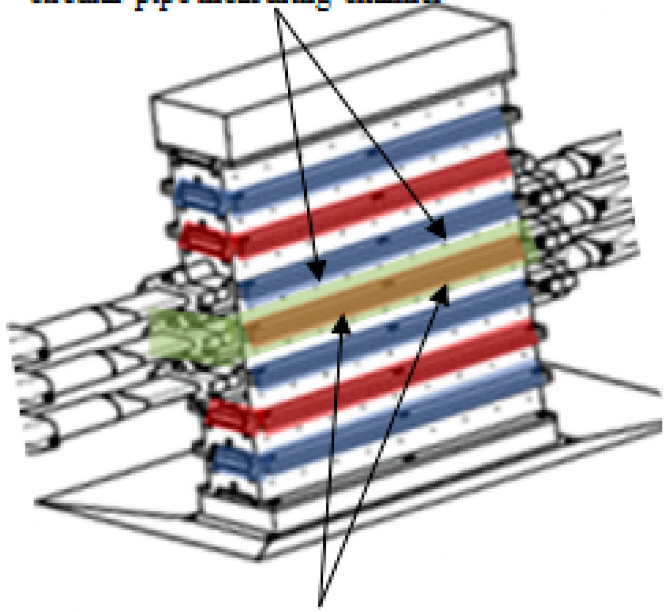

Drilled hole to check $T_{p \operatorname{lose}}$ with thermocouples in plane below the circular pipe measuring channel

Figure 11. Schematic drawing of the test section with the flow in the hot and cold flat tubes marked in red and blue, the symmetry plane $\mathrm{T}_{\text {plane }}$ between the flat tubes marked in green, and the system boundary for deriving Equation (1). Reproduced with permission from [16], published by Elsevier 2021.

$$
\begin{gathered}
\Delta \mathrm{p}_{\mathrm{fr}} \propto \frac{\mathrm{F}_{\mathrm{fr}}}{\mathrm{A}}=\frac{6 \pi \cdot \eta \cdot \mathrm{u} \cdot \mathrm{d}_{\mathrm{h}}}{\mathrm{A}} \\
\Delta \mathrm{p}_{\mathrm{fo}} \propto \frac{\mathrm{F}_{\mathrm{fo}}}{\mathrm{A}}=\frac{0.5 \cdot \rho \mathrm{u}^{2} \cdot \mathrm{A}_{\mathrm{c}} \cdot \mathrm{c}_{\mathrm{w}}}{\mathrm{A}} \\
\Delta \mathrm{p}=\Delta \mathrm{p}_{\mathrm{fr}}+\Delta \mathrm{p}_{\mathrm{fo}}
\end{gathered}
$$

Since the friction pressure drop $\Delta \mathrm{p}_{\mathrm{fr}}$ is proportional to the velocity $\mathrm{u}$ and the form pressure drop $\Delta \mathrm{p}_{\mathrm{fo}}$ to the square of the velocity $\mathrm{u}$, Equation (15) was assumed for the total pressure drop with the constants $\mathrm{D}_{1}$ and $\mathrm{E}_{1}$. The Hagen number, $\mathrm{Hg}$, was used in addition to the friction factor to express the pressure drop in dimensionless form using Equation (8).

$$
\begin{gathered}
\Delta \mathrm{p}=\mathrm{D}_{1} \cdot \operatorname{Re}+\mathrm{E}_{1} \cdot \operatorname{Re}^{2} \\
\mathrm{Hg}=\frac{\Delta \mathrm{p}}{\mathrm{L}} \cdot \frac{\mathrm{d}_{\mathrm{h}}{ }^{3}}{\rho \cdot v^{2}}=\frac{\mathrm{f}_{\mathrm{D}}}{2} \cdot \operatorname{Re}^{2}
\end{gathered}
$$


Consequently, it is possible to compare the two parts-friction and form drag-on the total pressure drop by the quantity of the two constants D (measure for friction drag) and $\mathrm{E}$ (measure for form drag) in Equation (9), which results from Equation (7).

$$
\frac{\mathrm{Hg}}{\operatorname{Re}}=\mathrm{D}+\mathrm{E} \cdot \operatorname{Re}
$$

By plotting $\mathrm{Hg} / \mathrm{Re}$ vs Re, the axis intercept $\mathrm{D}$ becomes a measure for the friction drag, and the slope E becomes a measure for the form drag. In addition, the change in slope for higher Reynolds numbers indicates a change in flow regime boundary, which is the end of the laminar flow regime [25] (reproduced with permission from Section 3, pages 6-7 in [16], published by Elsevier 2021).

\section{Results and Discussion}

Experimental data for heat transfer coefficients and pressure drop were determined for a Reynolds number range between $40<\operatorname{Re}<3500$ and Prandtl numbers between $8<\operatorname{Pr}<60$. The test fluid was a water-glycol mixture with a mass fraction of water of $\mathrm{x}_{\mathrm{m}}=0.477$. Table 3 shows the parameter combinations during the experiments in flat tubes with and without passive inserts and the number of data points determined for each of them. These conditions are typical for the liquid side of single-phase flat tube heat exchangers in automotive applications.

Table 3. Amount of test data for specific Prandtl and Reynolds number ranges.

\begin{tabular}{cccccc}
\hline Pr & Re & $\begin{array}{c}\text { Flat Tube without } \\
\text { Passive Inserts }\end{array}$ & $\begin{array}{c}\text { Flat Tube with } \\
\text { “Winglets” }\end{array}$ & $\begin{array}{c}\text { Flat Tube with } \\
\text { Cylindrical Pins }\end{array}$ & $\begin{array}{c}\text { Flat Tube with } \\
\text { Wave-Shaped Bumps }\end{array}$ \\
\hline 8 & $200-3500$ & 27 & 9 & 17 & 9 \\
11 & $150-2700$ & 22 & 13 & 0 & 0 \\
13 & $190-2000$ & 9 & 9 & 15 & 9 \\
15 & $170-1600$ & 11 & 11 & 0 & 0 \\
17 & $150-1500$ & 8 & 9 & 14 & 9 \\
22 & $120-1300$ & 8 & 9 & 9 & 9 \\
26 & $90-1500$ & 13 & 10 & 22 & 9 \\
32 & $75-800$ & 9 & 9 & 11 & 9 \\
36 & $70-750$ & 8 & 9 & 30 & 0 \\
40 & $50-650$ & 8 & 9 & 15 & 0 \\
50 & $45-500$ & 0 & 9 & 0 & 0 \\
60 & $40-400$ & 0 & 115 & 0 & 63 \\
Total & & 123 & 9 & 133 & 0 \\
\hline
\end{tabular}

In the following subsections, we discuss the results along the following order: First in Section 4.1, experimental data for flat tube flow without passive inserts is compared with appropriate literature data in order to further validate the experimental procedure. Second, in Section 4.2, the heat transferring surface and the specific surface, which is the heat transferring surface per fluid volume of all flat tube channels with and without passive inserts are compared. Heat transfer and pressure drop for flat tube flow with three different types of passive inserts are presented in Section 4.3. Here, the influence of passive inserts on the flow regime boundary and on the pressure drop as well as on the heat transfer mechanisms are analyzed. Finally, we discuss the trade-off between heat transfer enhancement and pressure drop increase with the help of an efficiency assessment, for which we used an energetic and an exergetical analysis presented in Section 4.4.

\subsection{Validation for Flat Tube without Passive Inserts}

The detailed validation for heat and momentum transfer inside a flat tube without passive inserts is shown in Bertsche et al. [16]. In the following we sum up the most important points. For further details, the reader is referred to Bertsche et al. [16]. 


\subsubsection{Heat Transfer}

Based on a correlation for calculation of heat transfer in flat tubes without passive inserts for laminar flow proposed by Garimella et al. [26], we compared our results for flat tube without passive inserts for laminar flow with this correlation. In order to apply this correlation, it is required to know the Nusselt number $\mathrm{Nu}_{\mathrm{fd}}$ for a fully developed laminar flow under the present thermal boundary condition of uniform wall temperature (UWT). Therefore, we used a correlation proposed by Shah and Bhatti [27] for flat tubes. A total of $81 \%$ of all data shown in [16] were predicted by the correlation of Garimella et al. [26], within the experimental error.

\subsubsection{Pressure Drop}

Using a correlation, which was also proposed by Shah and Bhatti [27], for calculation of the Darcy friction factor for laminar flow in flat tubes, we proved that $90 \%$ of all experimental data were within the measurement accuracy.

\subsection{Geometrical Analysis of Flat Tube Channels with and without Passive Inserts}

In order to evaluate the different heat transfer mechanisms and the influence of passive inserts on pressure drop, boundary layer, and bulk flow, the heat transferring surface A and the specific surface $S_{V}$, are listed in Table 4 for all flat tube channels. The passive inserts investigated here only increased the heat transferring surface by $0.8 \%$ to $1.1 \%$. The specific surface of the flat tube with "winglets" was increased by $5.8 \%$, which is in contrast to the $1.1 \%$ increase with cylindrical pins. The reason lies in the internal fluid volume, which is decreased much further than when using pins in the designs considered here (see Section 2.1 for background on that). Using wave-shaped bumps, which grow "inside" and "outside" the flat tube, the inner volume was equivalent to the volume of the flat tube without passive inserts, but the heat transfer surface was increased by $2.1 \%$, causing a specific surface increase of $3.6 \%$.

Table 4. Heat transfer surface A and specific surface for flat tube channels with and without passive inserts.

\begin{tabular}{ccccc}
\hline Flat Tube Channel & $\mathbf{A} / \mathbf{m}^{2}$ & $\left(\mathbf{A}_{\mathbf{w}}-\mathbf{A}_{\mathbf{w} / \mathbf{o}}\right) / \mathbf{A}_{\mathbf{w} / \mathbf{o}} / \mathbf{o}$ & $\mathbf{S}_{\mathbf{V}} / \mathbf{m}^{2} / \mathbf{m}^{3}$ & $\mathbf{S}_{\mathbf{V}} / \%$ \\
\hline w/o passive inserts & $6.75 \times 10^{-3}$ & - & 1907 & - \\
w/"winglets" & $6.82 \times 10^{-3}$ & 1.0 & 2018 & 5.8 \\
w/cylindrical pins & $6.80 \times 10^{-3}$ & 0.7 & 1928 & 1.1 \\
w/wave-shaped bumps & $6.90 \times 10^{-3}$ & 2.2 & 1976 & 3.6 \\
\hline
\end{tabular}

\subsection{Heat and Momentum Transfer without and with Passive Inserts}

Passive inserts as described in Figures 5-7 cause an increase in pressure drop as well as in heat transfer. The corresponding results are shown in Figures 12 and 13. Heat transfer for flat tube with "winglets" and cylindrical pins was increased approximately in the same range. It should be noted again that this was the result of the specific design of the pin arrangement and not a general feature of pins as passive inserts. A quite different behavior was shown for the flat tube with wave-shaped bumps. Heat transfer was enhanced particularly for high Reynolds numbers, whereas pressure drop was already exceeding that of pin and winglet channels for low Reynolds numbers.

Since the passive inserts increase the heat transferring surface by approximately $2 \%$, this would only result in a heat transfer enhancement of $<3 \%$. Thus, there must be other heat transfer mechanisms that are responsible for a heat transfer enhancement of up to $200 \%$ for both passive inserts. Nonetheless, before discussing potential reasons, an analysis of pressure drop is provided. 


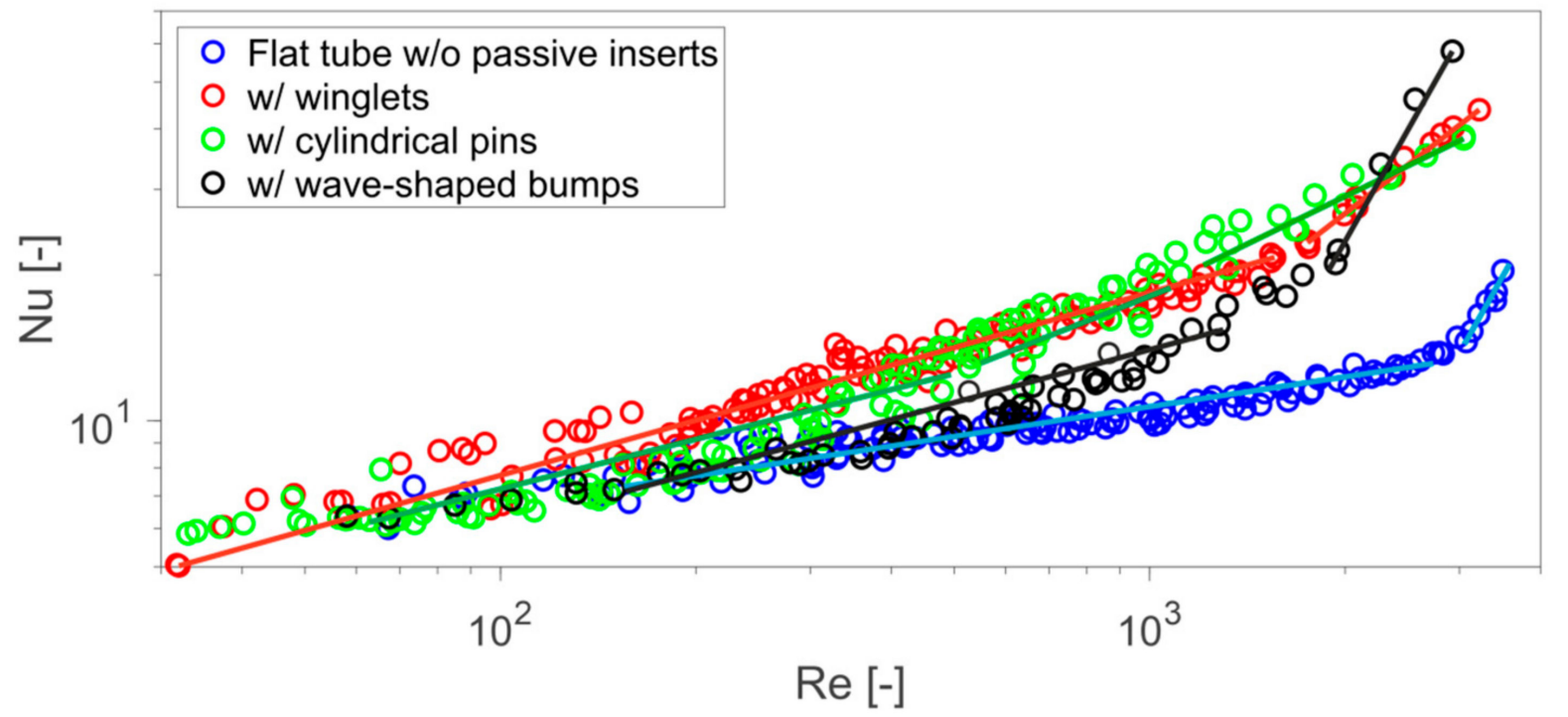

Figure 12. Heat transfer results for flat tube without passive inserts as well as with "winglets", cylindrical pins, and wave-shaped bumps.

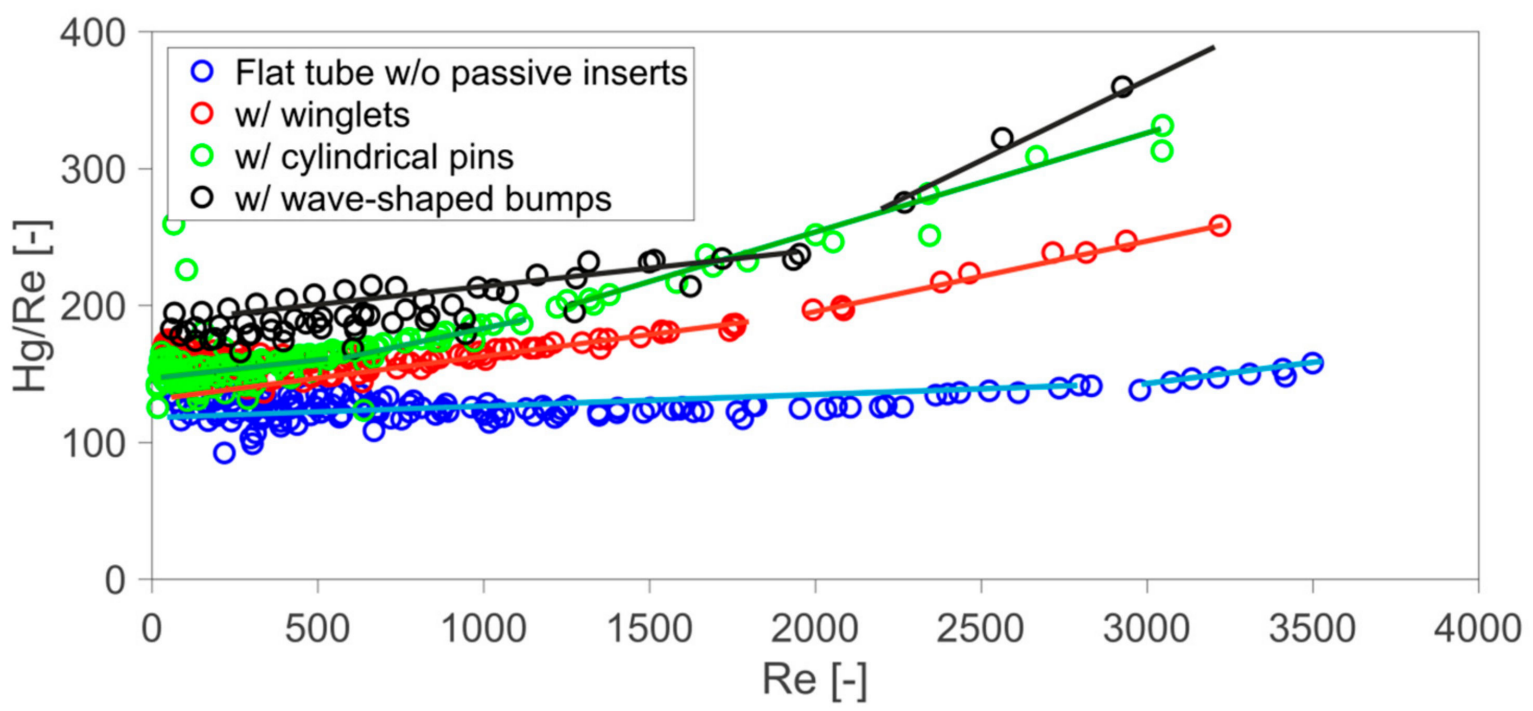

Figure 13. Pressure drop results for flat tube without passive inserts as well as with "winglets", cylindrical pins, and wave-shaped bumps.

\subsubsection{Friction and Form Drag Analysis}

The so called "winglets", with their low insert height (height to channels height of 0.325), mainly influence the near wall region, rather than the core flow within the flat tube. Therefore, the drag forces, which arise from pressure differences over the passive inserts surface (see value for $C$ with passive inserts in Table 5) increased compared with a flat tube without passive inserts, but must be lower compared to the pins, with their insert height which is equal to the flat tube height. With their form, "winglets" will mainly influence the flow in near wall region, increasing shear stress, resulting in an increase in friction pressure loss and consequently disturbing the formation of hydrodynamic and thermal boundary layer. In contrast to the situation in the flat tube channel without passive inserts, where the boundary layer formation starts from the inlet of the channel, with "winglets", the formation of boundary layer is continuously disturbed in flow direction and has to reform again. 
Table 5. Measures (slope $\mathrm{C}$ and axis intercept B from $\mathrm{Hg} / \mathrm{Re}$ vs Re plot) for friction $\mathrm{B}$ and form C drag pressure drop.

\begin{tabular}{ccc}
\hline Flat Tube Channel & $\begin{array}{c}\text { Axis Intercept B in Hg/Re vs. Re Plot } \\
\text { (Measure for Friction Drag Pressure Drop) }\end{array}$ & $\begin{array}{c}\text { Slope C in Hg/Re vs. Re Plot } \\
\text { (Measure for Form Drag Pressure Drop) }\end{array}$ \\
\hline w/o passive inserts & 120 & 0.0048 \\
w/“winglets" & 150 & 0.0200 \\
w/cylindrical pins & 138 & 0.0430 \\
w / wave-shaped bumps & 185 & 0.0200 \\
\hline
\end{tabular}

Using pins, the form drag pressure drop was significantly enhanced because the core flow with high local velocity components in flow direction was disturbed by the cylindrical pin inserts. Consequently, high local pressure differences arose around the pin surface, resulting in higher form drag pressure drop compared with non-pin inserts like "winglets" even in a design with just 35 cylindrical pins compared with 132 "winglets".

It is known from other publications [6-9] that pins are used to induce transient flow structures, such as the Karman vortex street and turbulence. In most of the investigations dealing with pin or pin fin structures as passive inserts in different kinds of tubes or channels a turbulent air flow is used. This results in an optimized pin fin design and in a pin fin arrangement in the channel, which could not be transferred to the present situation in flat tube channels with a liquid coolant fluid with a significantly higher Prandtl number and at lower Reynolds numbers, leading to a purely laminar flow in the corresponding flat tube channel without passive inserts. At this stage it must be stated that the available results and design suggestions from the literature [7-9,28,29] for an optimized pin fin structure cannot be used for flat tube heat exchangers since the pressure drop would be far too high, as too many pin inserts would be used.

This finding confirmed that no suitable insight in using pins in flat tube channels for the present Prandtl and Reynolds number range under the boundary condition of moderate pressure drop increase was available. Since the increased Prandtl number $8<\operatorname{Pr}<60$ was caused primarily by an increased viscosity, the pressure drop also increased, which forced engineers to spend fewer pins inside the channel to enable the already used coolant pumps, i.e., in automotive industry, to pump the flow.

However, the development of the flat tube channel with cylindrical pins is not part of this contribution, yet the background and why exactly this geometry and arrangement were chosen shall be briefly illuminated.

Using wave-shaped bumps, the friction pressure drop was increased significantly, see $C$ value in Table 5, because of the huge amount of inserted bumps with a very small insert height. The small insert height was exactly the reason why the form drag pressure drop was not significantly increased but instead matched the level of the "winglets" inserts. Because of the low velocity components in the near wall region, where the peak of the wave-shaped bumps is located, quite low pressure differences at the bump surfaces were present. It should be noted that the amount of bumps was chosen so as to create a comparable pressure drop level over all Reynolds and Prandtl numbers and the same total pressure drop as with the flat tube channel with "winglets". This provides a good foundation for a discussion of potential reasons for the characteristic differences in heat transfer and pressure drop as an effect of the different passive inserts.

\subsubsection{Flow Regime Boundary and Heat Transfer Mechanism Analysis}

Pressure drop results are presented in Figure 13 using the dimensionless numbers Hagen, $\mathrm{Hg}$, and Reynolds number, Re. The heat transfer results with Nusselt number $\mathrm{Nu}$ and Reynolds number Re are presented in Figure 12.

Since we have already presented results for heat transfer and pressure drop for the two channels without and with winglets as passive inserts, we have shortened the following explanations to the most relevant topics for the extended investigation within this contri- 
bution, focusing on two other passive inserts and the efficiency assessment of all types of passive inserts. The following results were determined for:

- $\quad$ Flat tube without passive inserts:

End of laminar flow regime occurring at $\operatorname{Re}_{\text {crit }}=2800$, indicated by the change in the slope for pressure drop results $\Delta(\mathrm{Hg} / \mathrm{Re}) / \Delta \mathrm{Re}$, presented in Figure 13.

- Confirmation of change in slope for heat transfer results $\Delta \mathrm{Nu} / \Delta \operatorname{Re}$ at $\operatorname{Re}_{\text {crit }}=2800$ in Figure 12.

- $\quad$ Flat tube with winglets:

$0 \quad$ End of laminar flow regime occurring at $\operatorname{Re}_{\text {crit }}=1500$, indicated by the change in the slope for pressure drop results $\Delta(\mathrm{Hg} / \mathrm{Re}) / \Delta \mathrm{Re}$, presented in Figure 13. Therefore, for $\operatorname{Re}>1500$ we assume that flow separation and local turbulences at the surface of the passive inserts are induced, which changes the character of the flow from laminar to turbulent.

$0 \quad$ These experimental results are confirmed by a numerical investigation with the exact same flat tube channel with winglets by Forooghi et al. [18], who concluded the following:

$>\quad$ "The flow is fully laminar and steady at $\operatorname{Re}=1000$ and turbulent at $\operatorname{Re}=2710$. At $\operatorname{Re}=1500$, turbulence transition is already triggered by formation of unsteady vortices in the region with inserts."

$>\quad$ "Destruction and reformation of the boundary layer has shown to be the main heat transfer enhancement mechanism due to passive inserts. This mechanism is equally in action in both laminar and turbulent regimes."

- Confirmation of change in slope for heat transfer results $\Delta \mathrm{Nu} / \Delta \mathrm{Re}$ at $\operatorname{Re}_{\text {crit }}=1500$ in Figure 12.

For flat tube with pins and wave-shaped bumps, the results are explained in detail as follows, with more explanations, starting with the flat tubes with cylindrical pins.

Due to the Reynolds number range investigated, in the flat tube without passive inserts only laminar flow conditions were present, whereas laminar and transitional flow conditions were present with passive inserts. With pin inserts, two characteristic changes in the slope $\Delta(\mathrm{Hg} / \mathrm{Re}) / \Delta \operatorname{Re}$ for pressure drop results existed for $\operatorname{Re}_{\text {crit }, 1}=550$ and $\operatorname{Re}_{\text {crit, }, 2}=1200$. With the assumption of an analogy to flow around a single cylinder according to Schlichting's "boundary layer theory" [30], the first change in slope must indicate the end of the laminar flow regime with no flow separation, with a fixed pair of symmetric vortices directly downstream of the pin, or with laminar vortex street downstream of the pin. Following the assumption of an analogy to flow around a single cylinder [30], the laminar flow regime boundary was expected to occur for $\operatorname{Re}_{\mathrm{p}}<150$, which corresponded to $\operatorname{Re}_{\mathrm{fl}}=525$, see Table 6. The indices $\mathrm{p}$ and fl reflect the characteristic length calculated either using the pin diameter " $\mathrm{p}$ " or the hydraulic diameter of the flat tube " $\mathrm{fl}$ " without passive inserts, which was used for calculating the Reynolds number. Since the cylindric diameter is typically used for the flow around a cylinder, for Rep, the pin diameter of $d=0.6 \mathrm{~mm}$ was used. For $\operatorname{Re}_{\mathrm{fl}}$ the flat tube hydraulic diameter was used as the characteristic length in order to calculate the Reynolds number, which was $d_{h}=2.08 \mathrm{~mm}$.

Table 6. Flow regime boundary for flow around single cylinder [30] compared with flow regime boundaries in flat tube with cylindrical pins determined from experiment.

\begin{tabular}{cccc}
\hline Flow Regime According to [30] & $\mathbf{R e}_{\mathrm{p}}$ Taken from [30] & $\boldsymbol{R e}_{\mathrm{fl}}$ Calculated from $\boldsymbol{R e}_{\mathrm{p}}$ [30] & $\begin{array}{c}\boldsymbol{R e}_{\mathrm{fl}} \text { Determined from Exp. Data, see } \\
\text { Figures 11 and 12 }\end{array}$ \\
\hline Laminar flow & $<150$ & $<522$ & $<550$ \\
Transition to turbulence & $150<\mathrm{Re}_{\mathrm{p}}<350$ & $522<\mathrm{Re}_{\mathrm{fl}}<1225$ & $550<\mathrm{Re}_{\mathrm{fl}}<1200$ \\
Fully turbulent flow & $\operatorname{Re}_{\mathrm{p}}>400$ & $\operatorname{Re}_{\mathrm{fl}}>1225$ & $\operatorname{Re}_{\mathrm{fl}}>1200$ \\
\hline
\end{tabular}

The subsequent flow regime, which was expected to occur for $150<\operatorname{Re}_{\mathrm{p}}<350$ [30], which corresponded to $525<\operatorname{Re}_{\mathrm{fl}}<1225$, was characterized by transition to turbulence 
in the vortex downstream of the pin and an increase in pressure drop and heat transfer due to local pressure differences and enhanced convective exchange of heat inside the flat tube, which occurred for $550<\operatorname{Re}_{\text {crit, } 2}<1200$. For Reynolds numbers $\operatorname{Re}>1200$ the vortex street became fully turbulent, which caused a further increase in pressure drop, while it was of course also further reducing the thermal boundary layer, which enhanced the heat transfer significantly.

Using wave-shaped bumps, the heat transfer enhancement was quite low for Reynolds numbers $\operatorname{Re}<1000$. The small insert height did not affect the core flow; thus, no turbulence was induced. In addition, the formation of the boundary layer was also not affected for $\operatorname{Re}<1000$ since the Nusselt numbers were comparable with the flat tube without passive inserts, but the pressure drop was significantly increased for $\operatorname{Re}<1000$ since the entire amount of wave-shaped bumps seemed to effectuate a flow situation in a flat tube channel with reduced channel height. A significant heat transfer enhancement was present for Reynolds numbers $\operatorname{Re}>2000$, which was indicated by a change in the slope $\Delta(\mathrm{Hg} / \mathrm{Re}) / \Delta \operatorname{Re}$ and $\Delta \mathrm{Nu} / \Delta \mathrm{Re}$. It seems, that turbulence directly in the boundary layer was induced, which significantly reduced the thermal boundary layer thickness.

\subsection{Efficiency Assessment}

Since there are different methods for performing an efficiency assessment available in the literature, we want to summarize the most frequently used ones and compare the different approaches. As long as either pressure drop or heat transfer of several flat tubes with passive inserts stay in the same range, the efficiency can simply be rated by the difference between the other quantity. Since in most cases, especially when a broad parameter range is investigated, this is not true, the efficiency of different passive inserts has to be evaluated in another way. Both heat transfer, with finite temperature difference, and pressure drop, due to friction and form drag forces, produce exergetic losses. Because of occurring irreversibilities, despite an energy balance, it may also be useful to use entropy balance for efficiency assessment.

\subsubsection{Energetic Evaluation}

When focusing on energy aspects, a first possible approach to rate efficiency is to compare the heat transfer expressed, e.g., by the Nusselt number, with the pressure drop in one diagram. Figure 14 shows the data for all three flat tube channels discussed before for a Prandtl number of $\operatorname{Pr}=13$.

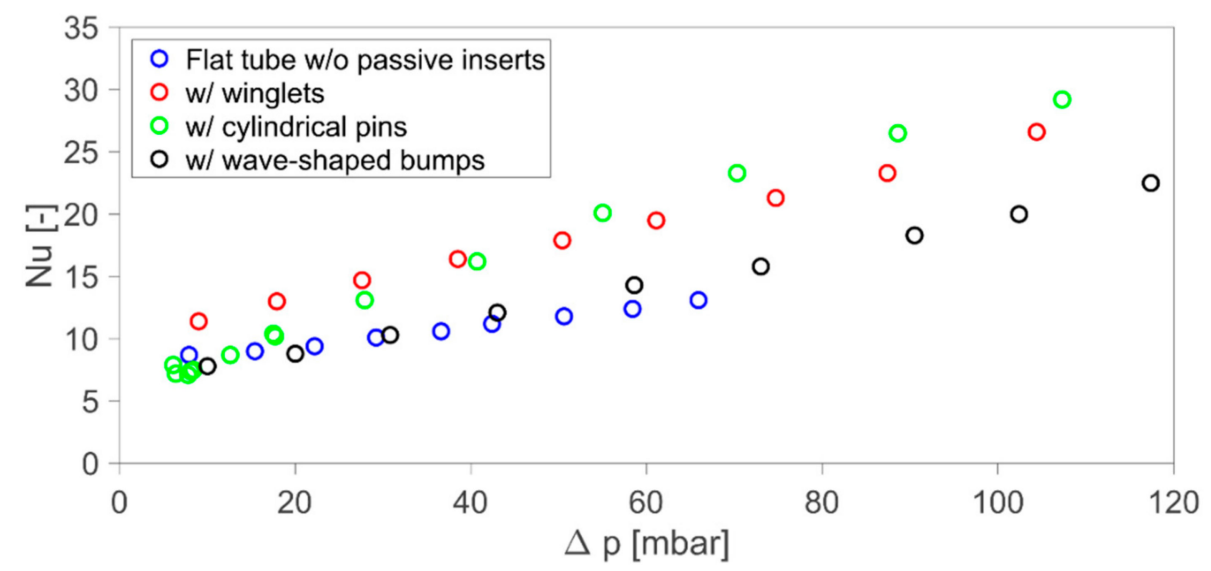

Figure 14. Efficiency in terms of Nusselt number $\mathrm{Nu}$ vs. pressure drop $\Delta \mathrm{p}$ for $\operatorname{Pr}=13$.

The results for the flat tube with cylindrical pins and the flat tube with "winglets" are quite similar. For low Reynolds number, the Nusselt number was slightly higher when using "winglets", while the pin tube showed highest values above approximately 50 mbar. Overall, the heat transfer increase with pressure drop was largest for the pin tube. The flat 
tube with wave-shapes bumps showed lower Nusselt numbers with similar pressure drop, which allowed rating this flat tube as being less efficient for $\operatorname{Pr}=13$ compared with the flat tube with "winglets" and the one with pins. Since the Reynolds number is not directly shown within Figure 13, the plot $\mathrm{Nu}$ vs Re shown in Figure 12 is helpful for interpretation concerning different underlaying flow regimes, since the Reynolds number is present within the diagram. However, no direct evaluation of "efficiency" in terms of heat transfer vs pressure drop is possible by plotting the results as shown in Figure 12. In order to help understanding the interpretation of the results in Figure 14, the additional information of Reynolds number shown in Figure 12 may help for energetic analysis interpretation. However, at this stage it is clear, that a more pleasant way plotting and interpreting the results would be helpful.

Another option to directly compare the increase in pressure drop and heat transfer enhancement of the flat tubes with different passive inserts with the flat tube channel without passive inserts is the thermal enhancement factor TEF, see Equation (10) [31,32]. For this, the quotient from Nusselt number with and without passive inserts is divided by the third root of the quotient from friction factor with and without passive inserts.

$$
\mathrm{TEF}=\frac{\mathrm{Nu}_{\mathrm{w}} / \mathrm{Nu}_{\mathrm{w} / 0}}{\left(\mathrm{f}_{\mathrm{w}} / \mathrm{f}_{\mathrm{w} / 0}\right)^{1 / 3}}
$$

The results for the thermal enhancement factor for the flat tube with passive inserts are shown in Figure 15 for a Prandtl number of $\operatorname{Pr}=13$, like before. The lowest TEF is presented for the wave-shaped bumps. For Reynolds numbers $\operatorname{Re}<1000$, the highest TEF is presented when using "winglets", but for $\operatorname{Re}>1000$, the situation changes, as higher TEF values for the use of cylindrical pins are present. Qualitatively, the results of an analysis according to Figures 13 and 15 are similar. If the total pressure drop is limited to a certain level, which is true for many practical applications, it is recommended to use an efficiency comparison as shown in Figure 13. Using the TEF, the total pressure drop is not presented, yet the corresponding Reynolds numbers are shown, which makes the TEF a suitable efficiency criterion for scientific investigations on passive inserts affecting, e.g., flow regime boundaries. The lowest TEF is shown for the wave-shaped bumps since within the experiments for $\operatorname{Pr}=13$, which were performed for $\operatorname{Re}<2000$, no turbulence was induced by the wave-shaped bumps. Since for a Prandtl number of $\operatorname{Pr}=13$ an increased fluid viscosity was present (compared with lower Prandtl numbers), it was not possible to investigate higher Reynolds numbers than $\mathrm{Re}=2000$ with the used fluid pumps.

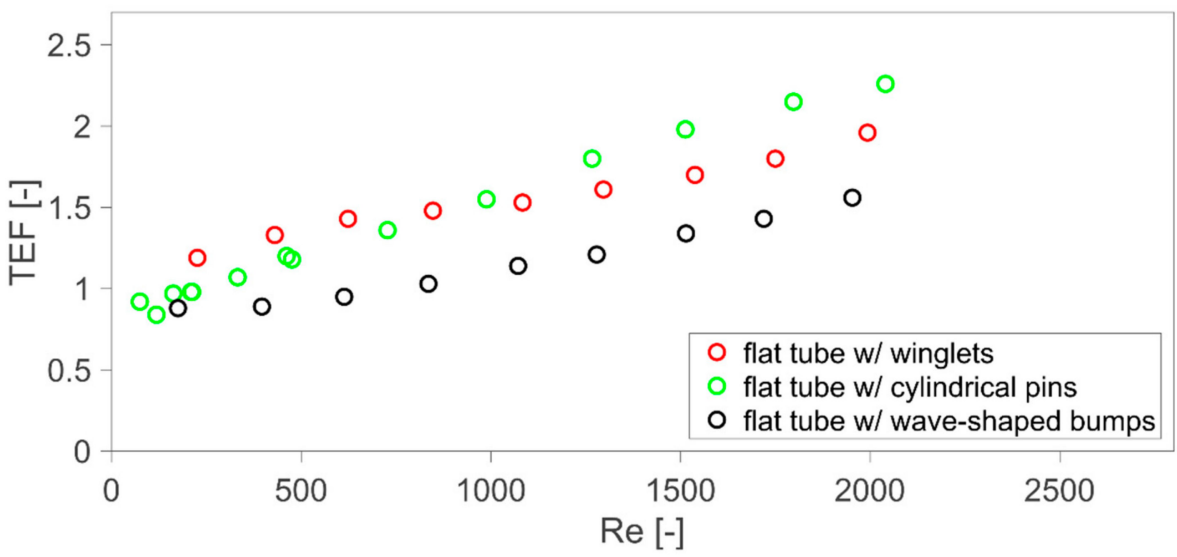

Figure 15. Efficiency in terms of thermal enhancement factor TEF for $\operatorname{Pr}=13$.

Following the ideas of Fan et al. [33], the quotient of the Nusselt number with passive inserts $\mathrm{Nu}_{\mathrm{w}}$ and without passive inserts $\mathrm{Nu}_{\mathrm{w} / \mathrm{o}}$ is plotted against the quotient of the respective dimensionless pressure drop $f_{w}$ and $f_{w / o}$. This graphic representation is called a performance evaluation plot (PEP) and shown in Figure 16. According to Fan et al. [33], 
this allows a cost-benefit analysis based on the distinction between increase in pumping power $\mathrm{P}$, pressure drop $\Delta \mathrm{p}$ enhancement, or increase in friction factor $\mathrm{f}$ if the following boundary conditions are met:

- Quasi-local test conditions are required, enabling the use of constant physical properties;

- The heat transferring surface of the channel without passive inserts is used for the calculation of heat transfer of all flat tubes with passive inserts;

- For the calculation of the Reynolds number, the characteristic length of the flat tube without passive inserts is used.

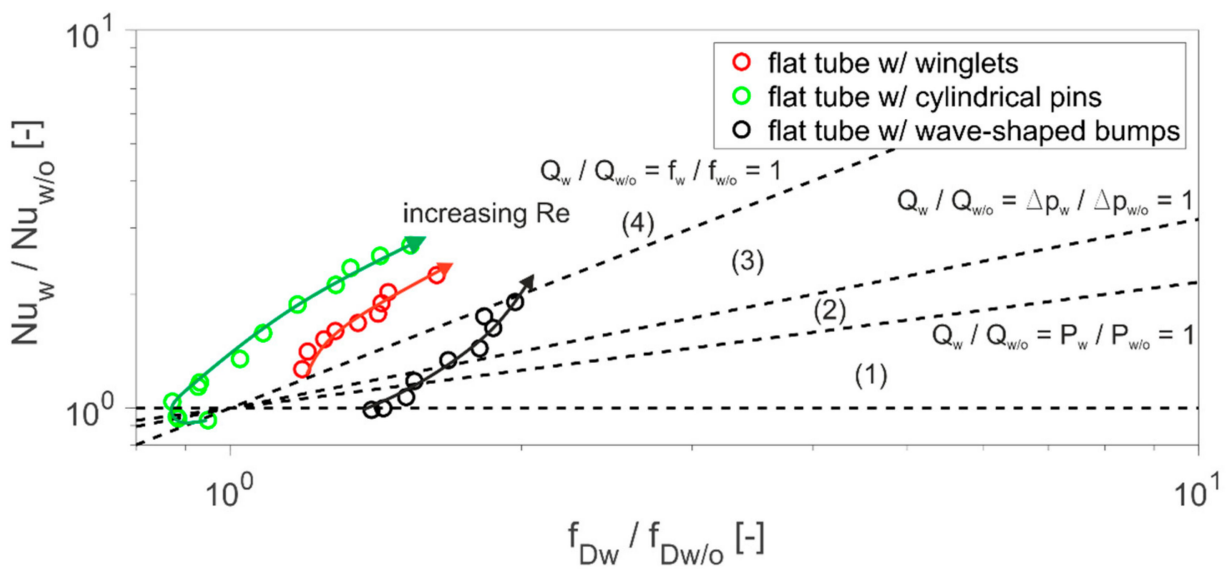

Figure 16. Efficiency in terms of performance evaluation plot (PEP) for $\operatorname{Pr}=13$.

These points can be considered as fulfilled for the experiments presented in this contribution. The correlation between the increase in pumping power, $\mathrm{P}_{\mathrm{w}} / \mathrm{P}_{\mathrm{w}} / \mathrm{o}$, the increase in pressure drop, $\Delta \mathrm{p}_{\mathrm{w}} / \Delta \mathrm{p}_{\mathrm{w} / \mathrm{o}}$, and the increase in friction factor, $\mathrm{f}_{\mathrm{w}} / \mathrm{f}_{\mathrm{w} / \mathrm{o}}$, are included as dashed lines in Figure 15. The correlation between the heat flow enhancement $\dot{\mathrm{Q}}_{\mathrm{w}} / \dot{\mathrm{Q}}_{\mathrm{w} / \mathrm{o}}$ and friction factor enhancement $\mathrm{f}_{\mathrm{w}} / \mathrm{f}_{\mathrm{w} / \mathrm{o}}$ is also presented as a bisecting line. $\mathrm{A}$ detailed derivation of the correlations is presented in [33].

In all areas 1-4, the heat transfer using passive inserts was increased. In area 1 , the heat transfer was increased without energy savings, as the heat flow increase was lower than the increase in pumping power. Area 1 and 2 are separated by the line, which indicates the same increase in heat transfer and pumping power. In area 2 the increase in heat transfer exceeded the enhanced pumping power. In area 3 , the increase in heat flow even exceeded the increase in pressure drop. In the most efficient area 4, the heat transfer enhancement exceeded the increase in friction factor. For Reynolds numbers $\operatorname{Re}<300$, no increase in heat transfer is presented for the use of cylindrical pins, as already presented in Figure 14 with TEF $<1$. Flat tube with cylindrical pins seems to be very efficient for $\operatorname{Re}>300$ since for $\operatorname{Re}>550$ turbulent structures behind the pins are induced mainly in the flow direction rather than crosswise to the flow direction, which allows a minimum increase in pressure drop, while convective heat transfer is still enhanced. In contrast with that, using "winglets", which mainly force a reformation of boundary layers rather than inducing turbulence, always operate in the most efficient regime.

The efficiency using wave-shaped bumps was enhanced with increasing Reynolds numbers. In contrast to pins and "winglets", the most efficient area 4 in the performance evaluation plot is not reached. With increasing Reynolds number, first, the increase in heat transferring surface of $2.1 \%$ affects the increase in efficiency since in the near-wall region, for low Reynolds numbers, low velocity components are present, which causes a minimum pressure drop increase. Further increasing the Reynolds number, higher velocity components arise in near-wall region, which disturb the formation of the boundary layer, resulting in a further efficiency enhancement, ranging from area 1 over 2 to 3. 
Compared with the plots for rating the efficiency, which are shown in Figures 14 and 15, the PEP allows the effect of the different insert types along four efficiency areas to be rated. It is also possible to account for a maximum pressure drop restriction with the PEP. Therefore, it is recommended to use the PEP for practical application, as it provides a lot of added relevant information.

\subsubsection{Energetic and Exergetic Evaluation}

Bejan $[34,35]$ developed a method to evaluate the efficiency based on entropy production or rather based on the minimization of irreversibilities. In its original form however, this method does not account for the heat transfer enhancement, nor pressure drop increase, which hinders its application for rating the efficiency of passive inserts used for heat exchangers. This fact has also been recognized by Zimparov and Vulchanov [36], who used Bejan's [34,35] method to extend the performance evaluation plot, proposed by Fan [33]. Zimparov [37] further extended this method in order to also account for different thermal boundary conditions (UWT and UWH-uniform wall heat flux) and for changing fluid temperature. Similar analyses have also been published by Prasad and Shen [38] and Hesselgreaves [39]. Following the derivation described above, we thoroughly investigate and apply the energetic and exergetic evaluation proposed by Zimparov [37] in this contribution.

The idea behind this method is to use the first and second law of thermodynamics and balance a differential volume element of the flat tube channel. A detailed derivation for the channel geometry used in this contribution can be found in Appendix A. Finally, Equation (11) for the total entropy production due to heat flow and pressure drop is derived. This equation can be divided in the part of entropy production due to heat flow $\dot{S}_{\text {gen,Nu }}$ and the one due to pressure drop $\dot{S}_{\text {gen, } \Delta \mathrm{p}}$. For comparing the entropy production of a flat tube without and with passive inserts, the entropy enhancement factor $\mathrm{N}_{\mathrm{S}}$, see Equation (13), is used.

$$
\begin{gathered}
\dot{\mathrm{S}}_{\text {gen }}=\dot{\mathrm{Q}} \cdot \frac{\mathrm{T}_{\mathrm{w}}-\mathrm{T}_{\text {out }}}{\mathrm{T}_{\text {in }} \cdot \mathrm{T}_{\text {out }}}+\frac{2 \cdot\left(\mathrm{U} / \mathrm{A}_{\mathrm{c}}\right)^{2}}{\mathrm{~d}_{\mathrm{h}}} \cdot \frac{\dot{\mathrm{M}}^{3} \cdot \mathrm{f}}{\rho^{2}} \cdot \frac{\mathrm{L}}{\mathrm{T}_{\mathrm{w}}} \\
\dot{\mathrm{S}}_{\text {gen }}=\dot{\mathrm{S}}_{\text {gen,Nu }}+\dot{\mathrm{S}}_{\text {gen }, \Delta \mathrm{p}} \\
\mathrm{N}_{\mathrm{S}}=\frac{\dot{\mathrm{S}}_{\text {gen }, \mathrm{w}}}{\dot{\mathrm{S}}_{\text {gen }, \mathrm{w} / \mathrm{o}}}
\end{gathered}
$$

In order to finally realize an energetic and exergetic evaluation, Zimparov [36] suggests comparing the quotient of $\mathrm{N}_{\mathrm{S}}$, which described the difference in entropy production with $\mathrm{Nu}_{\mathrm{w}} / \mathrm{Nu}_{\mathrm{w} / \mathrm{o}}$, which described the energetic enhancement in heat transfer, see Figure 17. The smaller this value, the fewer irreversibilities are produced, or rather the less entropy is produced per increase in heat transfer. In addition, a high increase in Nusselt number when using passive inserts also causes a small value for $\mathrm{N}_{\mathrm{S}} /\left(\mathrm{Nu}_{\mathrm{w}} / \mathrm{Nu}_{\mathrm{w} / \mathrm{o}}\right)$. Consequently, the most effective flat tube with passive inserts is represented in Figure 17 with the smallest values.

For Reynolds numbers $\operatorname{Re}<800$, the flat tube with winglets was the most effective flat tube for $\operatorname{Pr}=13$. Here the pressure drop increase for flat tubes with cylindrical pins for low Reynolds numbers was significantly higher compared with the one using winglets. The pins first started to induce heat transfer enhancing mechanisms, as described above, for Re $>550$, so that their $\mathrm{N}_{\mathrm{S}} /\left(\mathrm{Nu}_{\mathrm{w}} / \mathrm{Nu}_{\mathrm{w} / \mathrm{o}}\right)$-ratio was lowest there. 


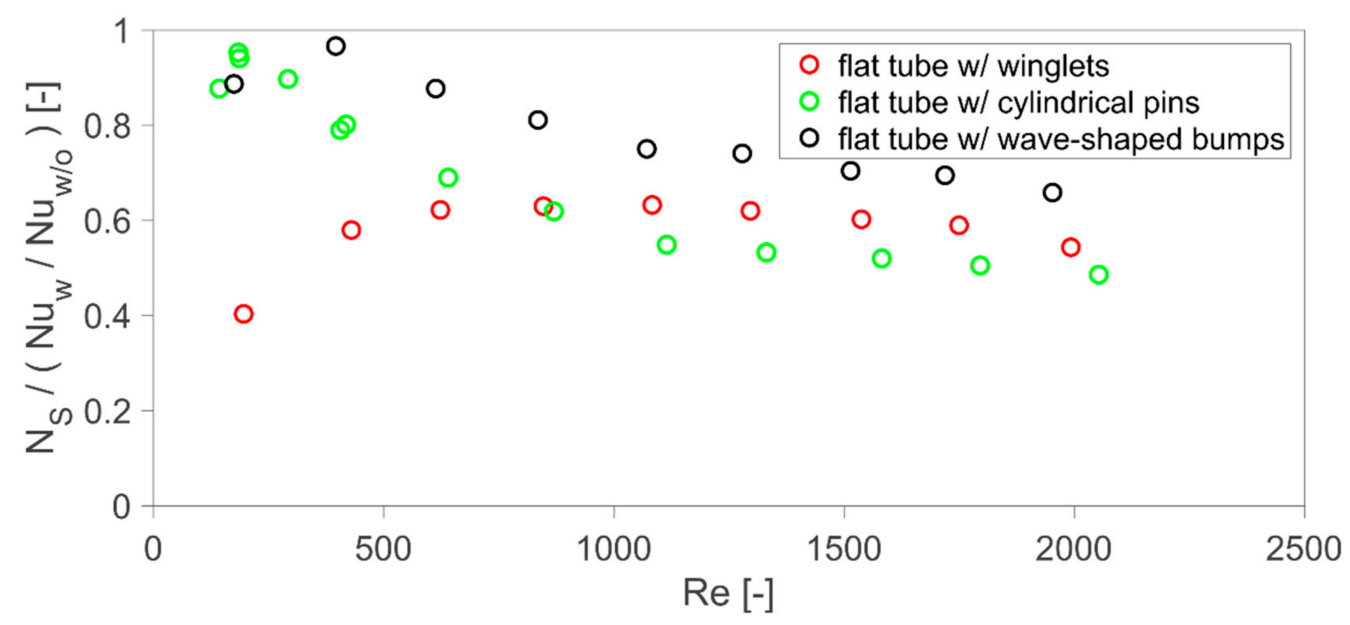

Figure 17. Extended efficiency criterion PEC according to Zimparov [37] for Pr $=13$.

However, the results presented in Figure 17 for the extended PEP, which he called PEC do not differ significantly from the results presented in Figure 15 for the thermal enhancement factor TEF, indicating that the entropy production due to heat transfer and pressure drop $\mathrm{N}_{S}$ is quite similar for all three types of flat tube with passive inserts. Which part of entropy production, either due to heat transfer or pressure drop, plays the main role for each passive insert is not presented here in a separate diagram, but can be calculated from Equations (11) and (12) since here, we want to focus overall efficiency.

$$
\begin{array}{r}
\mathrm{HTP}=\left(\frac{\dot{\mathrm{S}}_{\mathrm{gen}, \mathrm{Nu}, \mathrm{w}}}{\dot{\mathrm{S}}_{\mathrm{gen}, \mathrm{Nu}, \mathrm{w} / \mathrm{o}}}\right) /\left(\frac{\mathrm{Nu}_{\mathrm{w}}}{\mathrm{Nu}_{\mathrm{w} / \mathrm{o}}}\right) \\
\mathrm{PDP}=\left(\frac{\dot{\mathrm{S}}_{\mathrm{gen}, \Delta \mathrm{p}, \mathrm{w}}}{\dot{\mathrm{S}}_{\mathrm{gen}, \Delta \mathrm{p}, \mathrm{w} / \mathrm{o}}}\right) \cdot\left(\frac{\mathrm{f}_{\mathrm{w}}}{\mathrm{f}_{\mathrm{w} / \mathrm{o}}}\right) \\
\mathrm{TP}=1 /(\mathrm{HTP} \cdot \mathrm{PDP})
\end{array}
$$

In order to obtain a full picture of efficiency evaluation, we suggest to also take the entropy production due to pressure drop into account, which allows us to better distinguish between the contribution of heat transfer and pressure drop using the values for HTP and PDP from Equations (14) and (15). We name HTP as "heat transfer performance" and PDP as "pressure drop performance". As for high efficiency, HTP and PDP, both become small values, so we used the inverse of the product of the heat transfer performance HTP and pressure drop performance PDP according to Equation (16) in order to indicate high efficiency with high values, and we are calling this quantity total efficiency.

Figure 18 shows all three numbers as a function of Re. The lowest value for HTP, which corresponds to a significant increase in Nusselt number and simultaneously low increase in entropy production when using passive inserts, results for Reynolds numbers below $\operatorname{Re}=900$ for winglets and above $\operatorname{Re}=900$ for cylindrical pins. Because for Reynolds numbers above $\operatorname{Re}=900$, turbulent structures in flow direction are induced by the cylindrical pins, the Nusselt number increases significantly due to an increase in convective heat transfer, while pressure drop is also increased, but the highest value for PDP is shown exactly around $\operatorname{Re}=900$, when turbulence is induced.

It must be stated that we use here $\operatorname{Re}=800$ as the mean value for the range of $550<\operatorname{Re}<1200$, which has been determined as the range in which turbulence is induced by cylindrical pins. In addition, the effect on heat transfer performance as well as pressure drop performance in Figure 17 is clearly visible in this range, especially at $\operatorname{Re}=900$. The lowest values for pressure drop performance PDP, which means the lowest pressure drop increase and simultaneously the lowest entropy production due to pressure drop is presented for 
the flat tube with "winglets". Although wave-shaped bumps and pins are quite different in their effects and flow characteristics, the pressure drop performance is quite similar. The difference between the different flat tube types in total efficiency originates from the differences in heat transfer performance, where the wave-shaped bumps show less performance. For $\operatorname{Re}>1000$, the flat tube with cylindrical pins shows the highest total efficiency. Thus, for a Prandtl number of $\operatorname{Pr}=13$, it seems to be more effective for flat tube flow to induce streamwise vortices and turbulence in flat tubes, rather than using "winglets", which mainly destruct and reform the boundary layer [18]. It must be stated again here that both flat tube types were developed in order to realize the same heat transfer level, so the results should not be generalized.
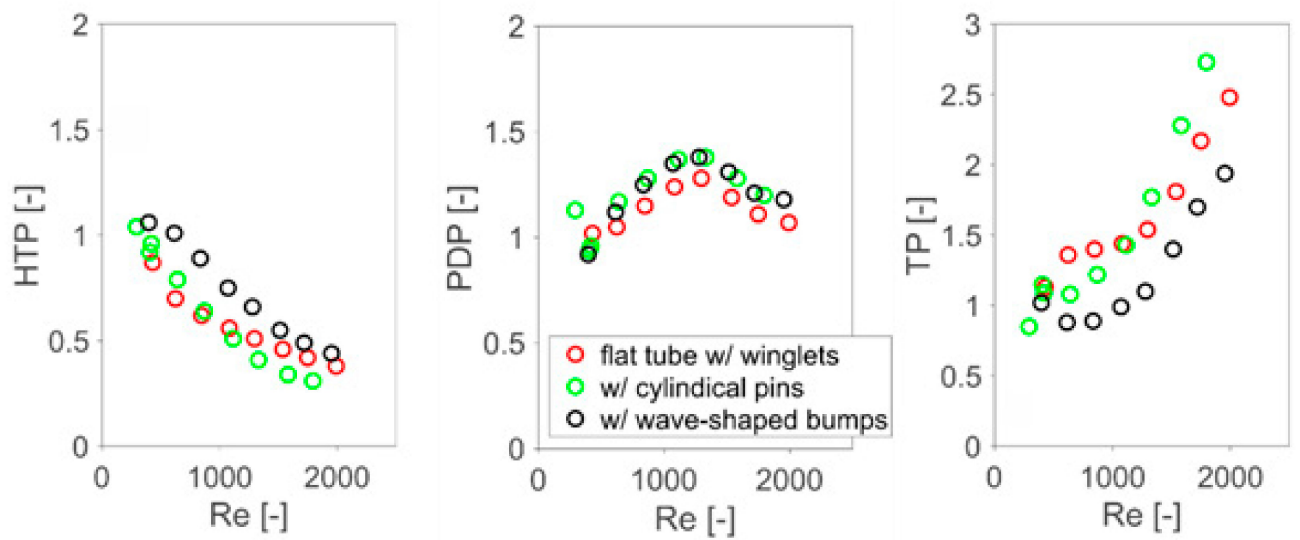

Figure 18. Heat transfer performance (HTP) and pressure drop performance (PDP) as well as total performance (TP) criterion for the tubes investigated in this contribution for $\operatorname{Pr}=13$.

Since the flat tube with "winglets" and that with wave-shaped bumps show the same form drag pressure drop, the difference in pressure drop performance PDP must be due to the differences in friction drag, which is higher for the wave-shaped bumps.

In summary, this newly proposed efficiency criterion, which fully accounts for energetic and exergetic evaluation, allows comparison of the different effects on heat transfer mechanisms and pressure drop, which are inducing turbulence, destructing the boundary layer, and inducing local pressure differences or shear stress, causing form and friction drag, respectively. However, the most application-oriented efficiency criterion seems to remain the performance evaluation plot since different areas of efficiency are directly indicated here. Maximum pressure drop restrictions are also very easy to track. On the other hand, this criterion does not allow analysis of the mechanisms of heat and momentum transfer, which are induced by the passive inserts. Plotting the total performance TP according to Equation (16) enables determination of the critical Reynolds numbers. For the flat tube with "winglets", a significant increase is visible for $\operatorname{Re}>\operatorname{Re}_{\text {crit }}=1500$, confirming the critical Reynolds number of the flat tube with "winglets". In addition, also the second critical Reynolds number for the flat tube with cylindrical pins can be confirmed to $\operatorname{Re}_{\text {crit }, 1}=1200$. Since only two data points for $\operatorname{Re}<500$ are shown for $\operatorname{Pr}=13$, it is not possible to finally judge the first critical Reynolds number, which should be found for $\operatorname{Re}_{\text {crit, } 2}=550$. Consequently, this criterion could be the means of choice for scientific and academic studies on passive heat transfer enhancement, evaluating the efficiency with respect to heat transfer and pressure drop enhancement, because it fully covers energetic and exergetic consideration of heat transfer and pressure drop.

\section{Conclusions}

Experiments were performed for a wide range of Reynolds and Prandtl numbers ranging from $8<\operatorname{Pr}<60$ and $40<\operatorname{Re}<3500$, for flat tubes without and with three different kind of passive inserts. The following points were understood for flat tube flow without and with passive inserts. 
Without passive inserts:

- $\quad$ Pressure drop is mainly induced by friction drag forces. The form drag forces contribute to a significantly minor part on the total pressure drop.

- Laminar flow is present for Reynolds numbers $\operatorname{Re}<2800$. With "winglets":

- Passive inserts mainly destruct and reform the boundary layer, and form drag and friction pressure drop are increased; however, pressure drop is mainly induced by friction forces.

- Laminar flow is present for Reynolds numbers $\operatorname{Re}<1500$. Turbulence is induced for $\operatorname{Re}>1500$.

- "Destruction and reformation of the boundary layer has shown to be the main heat transfer enhancement mechanism due to passive inserts. This mechanism is equally in action in both laminar and turbulent regimes." [18]

With "cylindrical pins":

- Passive inserts mainly reduce the critical Reynolds number, inducing turbulence at lower Reynolds numbers, as when using the other passive inserts, which have been investigated in this contribution. Turbulence is induced inside the core flow downstream of the pins for $\operatorname{Re}>550$.

- $\quad$ Form drag and friction pressure drop are increased; however, pressure drop is mainly induced by form drag forces, arising from local pressure differences.

With "wave-shaped bumps":

- $\quad$ Passive inserts mainly destruct and reform the boundary layer, and form drag and friction pressure drop are increased; however, pressure drop is mainly induced by friction forces.

- Turbulence is induced in the near-wall region, which significantly enhances the heat transfer for $\operatorname{Re}>2000$. Since in near-wall region relatively low velocity components are present, turbulence is induced not before $\operatorname{Re}_{\text {crit }}=2000$ is reached.

Based on the experimental results for heat transfer and pressure drop, different methods for efficiency assessment cited in literature were reviewed and discussed. Best pressure drop performance was calculated with winglets. Best heat transfer performance was calculated for cylindrical pins for $\operatorname{Re}>1000$ and for winglets for $\operatorname{Re}<1000$. Consequently, the total performance was best for cylindrical pins for $\operatorname{Re}<1000$ and for winglets for $\operatorname{Re}<1000$. The proposed concept for rating the efficiency, the "total performance", fully respects the energetic and exergetic aspects of heat transfer and pressure drop enhancement.

Author Contributions: Conceptualization, D.B., S.M. and T.W.; formal analysis, D.B. and P.K.; funding acquisition, T.W.; methodology, D.B., P.K. and S.M.; project administration, T.W.; software, D.B. and P.K.; supervision, T.W.; validation, D.B., P.K. and S.M.; visualization, D.B. and K.D.; writingoriginal draft, D.B.; writing-review and editing, D.B., K.D. and T.W. All authors have read and agreed to the published version of the manuscript.

Funding: This research was funded by MAHLE Behr GmbH \& Co. KG and BMWi, grant number 03ET1106A.

Acknowledgments: The fundamental analysis and experiments were performed during the first, second, and third authors' time as research assistants at the Karlsruhe Institute of Technology, Institute of Thermal Process Engineering. The authors would like to thank MAHLE Behr GmbH \& Co. KG and BMWi for their support of this research project. In addition, we would like to thank Klarissa Niedermeier, Dorothea Groß, Hannah Milena Kröhl, Tim Teichmann, Julyan Hanna, Michael Betz, and Konstantin Kapfer for their experimental work and for contributing ideas for this paper.

Conflicts of Interest: The authors declare no conflict of interest. The funders had no role in the design of the study; in the collection, analyses, or interpretation of data; in the writing of the manuscript; or in the decision to publish the results. 


\section{Nomenclature}

Latin symbols

A

$\mathrm{A}_{\mathrm{C}}$

$\mathrm{a}, \mathrm{b}, \mathrm{c}, \mathrm{d}, \mathrm{e}, \mathrm{f}$

$\mathrm{B}, \mathrm{C}, \mathrm{B}_{1}, \mathrm{C}_{1}$

$\mathrm{C}_{\mathrm{p}}$

$\mathrm{c}_{\mathrm{W}}$

$d, d_{h}$

$f_{D}$

$\mathrm{F}_{\text {fo }}, \mathrm{F}_{\mathrm{fr}}$

$\mathrm{h}$

$\mathrm{kA}$

L

$\dot{M}$

$\mathrm{p} / \mathrm{h}$

$\mathrm{p}, \Delta \mathrm{p}$

$\mathrm{Q}, \dot{\mathrm{q}}$

$\mathrm{R}$

$\mathrm{t} / \mathrm{h}$

$\mathrm{T}, \Delta \mathrm{T}$

$\mathrm{u}$

V

$\mathrm{x}_{\mathrm{m}}$

Greek symbols

$\alpha$

$\rho$

Subscripts

$\mathrm{Al}$

crit

cold

d

$\mathrm{fl}$

hot

in

lam

out

plane

turb

UWT

w

Dimensionless numbers

$\mathrm{Nu}=\frac{\alpha \cdot \mathrm{d}_{\mathrm{h}}}{\lambda}$

$\operatorname{Re}=\frac{\mathrm{u} \cdot \mathrm{d}_{\mathrm{h}}}{\eta}$

$\operatorname{Pr}=\frac{\eta \cdot \breve{c}_{\mathrm{p}}}{\lambda}$

$\mathrm{Hg}=\frac{\Delta \mathrm{p}}{\Delta \mathrm{l}} \cdot \frac{\mathrm{d}_{\mathrm{h}}{ }^{3}}{\rho \cdot v^{2}}$
Heat transfer surface $\left(\mathrm{m}^{2}\right)$

Cross section of the measuring channel $\left(\mathrm{m}^{2}\right)$

Geometrical distances $(\mathrm{m})$

Constant value (一)

Specific heat capacity $\left(\mathrm{J} \mathrm{kg}^{-1} \mathrm{~K}^{-1}\right)$

Drag coefficient (-)

Diameter (m), hydraulic diameter (m)

Darcy friction factor $(-)$

Flow forces due to form drag, due to friction drag $(\mathrm{N})$

Height of the flat tube channel (m)

Peak-to-trough roughness height $(\mathrm{m})$

Heat transmission coefficient $\left(\mathrm{W} \mathrm{K}^{-1}\right)$

Length $(\mathrm{m})$

Mass flow $\left(\mathrm{kg} \mathrm{s}^{-1}\right)$

Normal direction $(\mathrm{m})$

Pitch-to-height ratio of passive inserts (-)

Pressure (bar), pressure drop (bar)

Heat flow $(\mathrm{W})$, Heat flow density $\left(\mathrm{W} \mathrm{m}^{-2}\right)$

Heat transfer resistance $\left(\mathrm{K} \mathrm{W}^{-1}\right)$

Depth-to-height ratio of passive inserts (-)

Temperature $\left({ }^{\circ} \mathrm{C}\right)$, temperature difference $(\mathrm{K})$

Mean flow velocity $\left(\mathrm{m} \mathrm{s}^{-1}\right)$

Fluid volume inside flat tube $\left(\mathrm{m}^{3}\right)$

Mass fraction (-)

Heat transfer coefficient $\left(\mathrm{W} \mathrm{m}^{-2} \mathrm{~K}^{-1}\right)$

Dynamic viscosity $\left(\mathrm{kg} \mathrm{m}^{-1} \mathrm{~s}^{-1}\right)$

Thermal conductivity $\left(\mathrm{W} \mathrm{m}^{-1} \mathrm{~K}^{-1}\right.$ )

Kinematic viscosity $\left(\mathrm{m}^{2} \mathrm{~s}^{-1}\right)$

Density $\left(\mathrm{kg} \mathrm{m}^{-3}\right)$

Shear stress $\left(\mathrm{N} \mathrm{m}^{-2}\right)$

\section{Aluminum}

Indication of boundary between flow regimes

Cold flow

Pin diameter

Flat tube

Hot flow

Inlet

Laminar

Outlet

Plane in the aluminum shell

Turbulent

Uniform wall temperature

Wall

Nusselt number (-)

Reynolds number (-)

Prandtl number (-)

Hagen number $(-)$ 


\section{Appendix A}

With differential balancing energy (Equation (A1)) and exergy (Equation (A2)) inside the flat tube, the equation for the extended Performance Evaluation Criteria is derived in the following.

$$
\begin{aligned}
-\alpha \cdot\left(\mathrm{T}_{\mathrm{w}}-\mathrm{T}\right) \cdot \mathrm{U} \cdot \mathrm{dy} & =\rho \cdot \mathrm{c}_{\mathrm{p}} \cdot \mathrm{u} \cdot \mathrm{A}_{\mathrm{c}} \cdot \mathrm{dT} \\
\mathrm{d} \dot{\mathrm{S}}_{\text {gen }}+\frac{\mathrm{d} \mathrm{Q}}{\mathrm{T}_{\mathrm{w}}} & =\dot{\mathrm{M}} \cdot \mathrm{ds}
\end{aligned}
$$

Integrating Equation (A1) along the flat tube results in Equation (4) with the Stanton number St.

$$
\begin{gathered}
\int_{\mathrm{y}=0}^{\mathrm{y}=\mathrm{y}}-\alpha \cdot\left(\mathrm{T}_{\mathrm{w}}-\mathrm{T}\right) \cdot \mathrm{U} \cdot \mathrm{dy}=\int_{\mathrm{T}=\mathrm{T}_{\text {in }}}^{\mathrm{T}=\mathrm{T}} \rho \cdot \mathrm{c}_{\mathrm{p}} \cdot \mathrm{u} \cdot \mathrm{A}_{\mathrm{c}} \cdot \mathrm{dT} \\
\mathrm{T}_{\mathrm{w}}-\mathrm{T}=\left(\mathrm{T}_{\mathrm{w}}-\mathrm{T}_{\text {in }}\right) \cdot \exp \left\{-\mathrm{St} \cdot \frac{\mathrm{U}}{\mathrm{A}_{\mathrm{c}}} \cdot \mathrm{y}\right\} \\
\mathrm{St}=\frac{\mathrm{Nu}}{\operatorname{Re} \cdot \operatorname{Pr}}=\frac{\alpha}{\rho \cdot \mathrm{c}_{\mathrm{p}} \cdot \mathrm{u}}
\end{gathered}
$$

Further, assuming an incompressible fluid $\left(\mathrm{dH}=\mathrm{c}_{\mathrm{p}} \mathrm{dT}\right)$ and using the following thermodynamic relations $(\mathrm{T} \cdot \mathrm{ds}=\mathrm{dH}-\mathrm{V} \cdot \mathrm{dp})$ and $(\mathrm{dQ}=\dot{\mathrm{M}} \cdot \mathrm{dH})$, Equation (A2) is transformed to Equation (A6).

$$
\frac{\mathrm{d} \dot{\mathrm{S}}_{\text {gen }}}{\mathrm{dy}}=\dot{\mathrm{M}} \mathrm{c}_{\mathrm{p}} \cdot \frac{\mathrm{T}_{\mathrm{w}}-\mathrm{T}}{\mathrm{T} \cdot \mathrm{T}_{\mathrm{w}}} \cdot \frac{\mathrm{dT}}{\mathrm{dy}}+\frac{\dot{\mathrm{M}}}{\rho \cdot \mathrm{T}} \cdot\left(-\frac{\mathrm{dp}}{\mathrm{dy}}\right)
$$

Substituting $\mathrm{T}_{\mathrm{w}}=\mathrm{T}(\mathrm{y})+\Delta \mathrm{T}(\mathrm{y})$ and $\tau_{\mathrm{T}}=\Delta \mathrm{T} / \mathrm{T}$, we obtain Equations (A7) and (A8).

$$
\begin{aligned}
& \frac{\mathrm{d} \dot{\mathrm{S}}_{\text {gen }}}{\mathrm{dy}}=\dot{\mathrm{M}} \mathrm{c}_{\mathrm{p}} \cdot \frac{\Delta \mathrm{T}}{\mathrm{T} \cdot(\mathrm{T}+\Delta \mathrm{T})} \cdot \frac{\mathrm{dT}}{\mathrm{dy}}+\frac{\dot{\mathrm{M}}}{\rho \cdot \mathrm{T}} \cdot\left(-\frac{\mathrm{dp}}{\mathrm{dy}}\right) \\
& \frac{\mathrm{d} \dot{\mathrm{S}}_{\mathrm{gen}}}{\mathrm{dy}}=\dot{\mathrm{M}} \mathrm{c}_{\mathrm{p}} \cdot \frac{\Delta \mathrm{T}}{\mathrm{T}^{2} \cdot\left(1+\tau_{\mathrm{T}}\right)} \cdot \frac{\mathrm{dT}}{\mathrm{dy}}+\frac{\dot{\mathrm{M}}}{\rho \cdot \mathrm{T}} \cdot\left(-\frac{\mathrm{dp}}{\mathrm{dy}}\right)
\end{aligned}
$$

Due to the present quasi-local test conditions, one has $\tau_{\mathrm{T}} \ll 1$ and Equation (A9).

$$
\frac{\mathrm{d} \dot{\mathrm{S}}_{\mathrm{gen}}}{\mathrm{dy}}=\dot{\mathrm{M}} \mathrm{c}_{\mathrm{p}} \cdot \frac{\Delta \mathrm{T}}{\mathrm{T}^{2}} \cdot \frac{\mathrm{dT}}{\mathrm{dy}}+\frac{\dot{\mathrm{M}}}{\rho \cdot \mathrm{T}} \cdot\left(-\frac{\mathrm{dp}}{\mathrm{dy}}\right)
$$

Replacing the bulk temperature $\mathrm{T}(\mathrm{y})$ in Equation (A9) with Equation (A4), using Equations (A10) and (A11), and integrating the resulting equation over the entire flat tube length results in Equation (A12).

$$
\begin{gathered}
\frac{d p}{d y}=2 \cdot f \cdot \rho \cdot \frac{u}{d_{h}} \\
u=\frac{M}{A_{c} \cdot \rho} \\
\dot{S}_{\text {gen }}=\dot{M} c_{p} \cdot\left(-\frac{\left(T_{w}-T_{\text {in }}\right) \cdot \exp \left\{-S t \cdot \frac{U}{A_{c}} \cdot L\right\}}{T_{w}-\left(T_{w}-T_{\text {in }}\right) \cdot \exp \left\{-S t \cdot \frac{U}{A_{c}} \cdot L\right\}}+\frac{\left(T_{w}-T_{\text {in }}\right)}{T_{w}-\left(T_{w}-T_{\text {in }}\right)}\right. \\
\left.-\ln \frac{T_{w}-\left(T_{w}-T_{\text {in }}\right) \cdot \exp \left\{-S t \cdot \frac{U}{A_{c}} \cdot L\right\}}{T_{w}-\left(T_{w}-T_{\text {in }}\right)}\right)+\frac{2 \cdot \frac{U}{A_{c}}}{d_{h}} \cdot \frac{\dot{M}^{3} \cdot f}{\rho^{2}} \\
\cdot\left[-\frac{1}{S t \cdot \frac{U}{A_{c}} \cdot T_{w}} \cdot\left(\ln \frac{T_{\text {in }}}{T_{\text {out }}}-S t \cdot \frac{U}{A_{c}} \cdot L\right)\right]
\end{gathered}
$$


With the following equations (Equations (A13)-(A15)) the final equation results for the entropy production in Equation (A16), which is equal to Equation (11) used in this contribution.

$$
\begin{gathered}
\dot{\mathrm{Q}}=\dot{\mathrm{M}} \mathrm{c}_{\mathrm{p}} \cdot\left(\mathrm{T}_{\text {in }}-\mathrm{T}_{\text {out }}\right) \\
\ln \frac{\mathrm{T}_{\text {in }}}{\mathrm{T}_{\text {out }}}=\ln \left(1+\frac{\mathrm{T}_{\text {out }}-\mathrm{T}_{\text {in }}}{\mathrm{T}_{\text {in }}}\right) \cong \frac{\mathrm{T}_{\text {out }}-\mathrm{T}_{\text {in }}}{\mathrm{T}_{\text {in }}} \\
\frac{1}{\mathrm{St} \cdot \frac{\mathrm{U}}{\mathrm{A}_{\mathrm{c}}} \cdot \mathrm{L}} \cdot \frac{\mathrm{T}_{\text {out }}-\mathrm{T}_{\text {in }}}{\mathrm{T}_{\text {in }}}=\frac{\mathrm{T}_{\mathrm{w}}-\mathrm{T}_{\mathrm{m}}}{\mathrm{T}_{\text {out }}-\mathrm{T}_{\text {in }}} \cdot \frac{\mathrm{T}_{\text {out }}-\mathrm{T}_{\text {in }}}{\mathrm{T}_{\text {in }}}=\frac{\mathrm{T}_{\mathrm{w}}-\mathrm{T}_{\mathrm{m}}}{\mathrm{T}_{\text {in }}} \ll 1 \\
\dot{\mathrm{S}}_{\text {gen }}=\dot{\mathrm{Q}} \cdot \frac{\mathrm{T}_{\mathrm{w}}-\mathrm{T}_{\text {out }}}{\mathrm{T}_{\text {in }} \cdot \mathrm{T}_{\text {out }}}+\frac{2 \cdot\left(\mathrm{U} / \mathrm{A}_{\mathrm{c}}\right)^{2}}{\mathrm{~d}_{\mathrm{h}}} \cdot \frac{\dot{\mathrm{M}}^{3} \cdot \mathrm{f}}{\rho^{2}} \cdot \frac{\mathrm{L}}{\mathrm{T}_{\mathrm{w}}}
\end{gathered}
$$

\section{References}

1. Lau, S.C.; Kukreja, R.T.; McMillin, R.D. Effects of V-shaped rib arrays on turbulent heat transfer and friction of fully developed flow in a square channel. Int. J. Heat Mass Transf. 1991, 34, 1605-1616. [CrossRef]

2. Han, J.C.; Zhang, Y.M. High performance heat transfer ducts with parallel broken and V-shaped broken ribs. Int. J. Heat Mass Transf. 1992, 35, 513-523. [CrossRef]

3. Kumar, S.; Saini, R. CFD based performance analysis of a solar air heater duct provided with artificial roughness. Renew. Energy 2009, 34, 1285-1291. [CrossRef]

4. Chung, H.; Park, J.; Park, S.S.; Choi, S.M.; Rhee, D.-H.; Cho, H.H. Augmented heat transfer with intersecting rib in rectangular channels having different aspect ratios. Int. J. Heat Mass Transf. 2015, 88, 357-367. [CrossRef]

5. Turnow, J.; Kornev, N.; Isaev, S.; Hassel, E. Vortex mechanism of heat transfer enhancement in a channel with spherical and oval dimples. Int. J. Heat Mass Transf. 2011, 47, 301-313. [CrossRef]

6. Peng, Y. Heat Transfer and Friction Loss Characteristics of Pin Fin Cooling Configurations. J. Eng. Gas Turbines Power 1984, 106, 246-251. [CrossRef]

7. Armstrong, J.; Winstanley, D. A review of staggered array pin fin heat transfer for turbine cooling applications. ASME J. Turbomach. 1988, 110, 94-103. [CrossRef]

8. Metzger, D.E.; Berry, R.A.; Bronson, J.P. Developing heat transfer in rectangular ducts with staggered arrays of short pin fins. ASME J. Heat Transf. 1982, 104, 700-706. [CrossRef]

9. Wang, F.; Zhang, J.; Wang, S. Investigation on flow and heat transfer characteristics in rectangular ducts with drop-shaped pin-fins. Propuls. Power Res. 2012, 1, 64-70. [CrossRef]

10. Wongcharee, K.; Changcharoen, W.; Eiamsa-ard, S. Numerical investigation of flow friction and heat transfer in a channel with various shaped ribs mounted on two opposite ribbed walls. Int. J. Chem. React. Eng. 2011, 9, A26. [CrossRef]

11. Dewan, A.; Mahanta, P.; Raju, K.S.; Kumar, P.S. Review of passive heat transfer augmentation techniques. Proc. Inst. Mech. Eng. Part A J. Power Energy 2004, 218, 509-527. [CrossRef]

12. Bertsche, D.; Knipper, P.; Dietrich, B.; Wetzel, T. The Generalized Lévêque Equation and its application to circular pipe flow. Int. J. Heat Mass Transf. 2015, 90, 1255-1265. [CrossRef]

13. Bertsche, D.; Wetzel, T. Experimental set-up for investigation of passive heat transfer augmentation in water-air heat exchangers. In Proceedings of the 8th World Congress on Experimental Heat Transfer, Fluid Mechanics and Thermodynamics, Lisbon, Portugal, 16-20 June 2013.

14. Bertsche, D.; Knipper, P.; Wetzel, T. Experimental investigation on heat transfer in laminar, transitional and turbulent circular pipe flow. Int. J. Heat Mass Transf. 2016, 95, 1008-1018. [CrossRef]

15. Bertsche, D.; Knipper, P.; Kapfer, K.; Wetzel, T. Experimental investigation on heat transfer in laminar, transitional and turbulent circular pipe flow with respect to flow regime boundaries. Int. J. Heat Mass Transf. 2019, 145, 118746. [CrossRef]

16. Bertsche, D.; Meinicke, S.; Knipper, P.; Dubil, K.; Wetzel, T. The Generalized Lévêque Equation and its application to flat tubes without and with passive inserts. Int. J. Heat Mass Transf. 2021, 171, 121053. [CrossRef]

17. Herwig, H. Wärmeübertragung: Physikalische Grundlagen, 3. Erweiterte und Überarbeitete Auflage; Springer: Wiesbaden, Germany, 2014.

18. Forooghi, P.; Flory, M.; Bertsche, D.; Wetzel, T.; Frohnapfel, B. Heat transfer enhancement on the liquid side of an industrially designed flat-tube heat exchanger with passive inserts-Numerical investigation. Appl. Therm. Eng. 2017, 123, 573-583. [CrossRef]

19. Ghajar, A.J.; Madon, K.F. Pressure drop measurements in the transition region for a cylindrical tube with three different inlet configurations. Exp. Therm. Fluid Sci. 1992, 5, 129-135. [CrossRef]

20. Ghajar, A.J.; Tam, L.M. Flow regime map for a horizontal pipe with uniform wall heat flux and three inlet configurations. Exp. Therm. Fluid Sci. 1995, 10, 287-297. [CrossRef]

21. Ghajar, A.J.; Tam, L.M. Heat transfer measurements and correlations in the transition region for a cylindrical tube with three different inlet configurations. Exp. Therm. Fluid Sci. 1994, 8, 79-90. [CrossRef]

22. Kast, W. Pressure Drop in Single Phase Flow, VDI Heat Atlas, 2nd ed.; Springer Verlag: Berlin/Heidelberg, Germany, 2010; Chapter Lac 1-6. 
23. ISO/IEC GUIDE 98-3:2008; Uncertainty of Measurement-Part 3: Guide to the Expression of Uncertainty in Measurement (GUM:1995). ISO/IEC: Geneva, Switzerland, 2008.

24. Baehr, H.D.; Stephan, K. Wärme-und Stoffübertragung; Springer: Berlin, Germany, 2010; Chapter 2.2.5.1; pp. 154-161.

25. Della, A.; Torre, G.; Montenegro, G.R.; Tabor, M.; Wears, L. CFD characterization of flow regimes inside open cell foam substrates. Int. J. Heat Fluid Flow 2014, 50, 72-82. [CrossRef]

26. Garimella, S.; Dowling, W.J.; Van Der Veen, M.; Killion, J.D. The effect of simultaneously developing flow on heat transfer in rectangular tubes. Heat Transf. Eng. 2001, 22, 12-25. [CrossRef]

27. Shah, R.K.; Bhatti, M.S. Laminar Convective Heat Transfer in Ducts. In Handbook of Single-Phase Convective Heat Transfer; Kakac, S., Shah, R.K., Eds.; Wiley: New York, NY, USA, 1987; pp. 3.1-3.137.

28. VanFossen, G.J. Staggered Arrays of Short Pin. J. Eng. Gas Turbines Power 1982, 104, 268-274. [CrossRef]

29. Moon, M.A.; Kim, K.Y. Analysis and optimization of fan-shaped pin-fin in a rectangular cooling channel. Int. J. Heat Mass Transf. 2014, 72, 148-162. [CrossRef]

30. Schlichting, H.; Gersten, K. Boundary Layer Theory, 10th ed.; Springer: Berlin/Heidelberg, Germany, 2006.

31. Wang, G.L.; Yang, D.W.; Wang, Y.D.; Niu, X.; Zhao, L.; Ding, G. Heat Transfer and Friction Characteristics of the Microfluidic Heat Sink with Variously-Shaped Ribs for Chip Cooling. Sensors 2015, 15, 9547-9562. [CrossRef]

32. Park, J.S.; Han, J.C.; Huang, Y.; Ou, S.; Boyle, R.J. Heat transfer performance comparisons of five different rectangular channels with parallel angled ribs. Int. J. Heat Mass Transf. 1992, 35, 2891-2903. [CrossRef]

33. Fan, J.F.; Ding, W.K.; Zhang, J.F.; He, Y.L.; Tao, W.Q. A performance evaluation plot of enhanced heat transfer techniques oriented for energysaving. Int. J. Heat Mass Transf. 2009, 52, 33-44. [CrossRef]

34. Bejan, A. Entropy Generation Through Heat and Fluid Flow; CRC Press: New York, NY, USA, 1982.

35. Bejan, A. Entropy Generation Minimisation; Wiley: New York, NY, USA, 1996.

36. Zimparov, V.D.; Vulchanov, N.L. Performance evaluation criteria for enhanced heat transfer surfaces. Int. J. Heat Mass Transf. 1994, 37, 1807-1816. [CrossRef]

37. Zimparov, V.D. Extended performance evaluation criteria for enhanced heat transfer surfaces: Heat transfer through ducts with constant wall temperature. Int. J. Heat Mass Transf. 2000, 43, 3137-3155. [CrossRef]

38. Prasad, R.C.; Shen, J. Performance evaluation of convective heat transfer enhancement devices using exergy analysis. Int. J. Heat Mass Transf. 1993, 36, 4193-4197. [CrossRef]

39. Hesselgreaves, J.E. Rationalisation of second law analysis of heat exchangers. Int. J. Heat Mass Transf. 2000, 43, 4189-4204. [CrossRef] 